\title{
Simultaneous Pretreatment and Catalytic Conversion of Polyolefins into Hydrocarbon Fuels over Acidic Zeolite Catalysts
}

Ishaka Muhammad, George Manos*

Department of Chemical Engineering, University College London, London WC1E 7JE, UK

*Corresponding Author: g.manos@ucl.ac.uk

\section{Abstract}

The effect of pre-degradation treatment in catalytic pyrolysis of polymer was assessed using thermogravimetric analysis (TGA) and pyrolysis reactor experiments of different polymers on various catalysts. Intimate contact between the polymer and catalyst was achieved using physical, mechanical and thermal treatments. The results from the TGA analysis show that pre-degradation treatment has greatly improved the performance of the catalyst attaining maximum degradation at lower temperature. Pre-degradation treatment had increased the liquid yield and lowered the coke yield at various extents depending on the catalyst structure and acidity. The ZSM- 5 catalyst with high $\mathrm{Si} / \mathrm{Al}$ ratio showed maximum amount of $\left(\mathrm{C}_{5}-\mathrm{C}_{9}\right)$ and ZSM-5 with lower $\mathrm{Si} / \mathrm{Al}$ ratio has maximum percentage of $\left(\mathrm{C}_{14}-\mathrm{C}_{20}\right)$. Based on the performance of the pre-degradation treatment methods, normal mixing produced the maximum amount of lighter fractions and therefore predegradation treatment can serve to enhance the gasoline fraction while the diesel fraction can be optimised using the co-pressing method, where polymer and catalyst particles were thoroughly mixed and co-pressed together into mixed particles. Coke characterisation showed coke formed by linear low density polyethylene contained more volatile coke components while polypropylene coke had higher percentage of hard coke. ZSM-5 had lower retention of coke components with volatile coke precursors. The volatility of the coke increases while coke concentration and decreases as the catalyst amount decreases. Pre-degradation treatment facilitated the formation of soft coke components that are easy to remove in inert atmosphere. 


\section{Graphical Abstract}

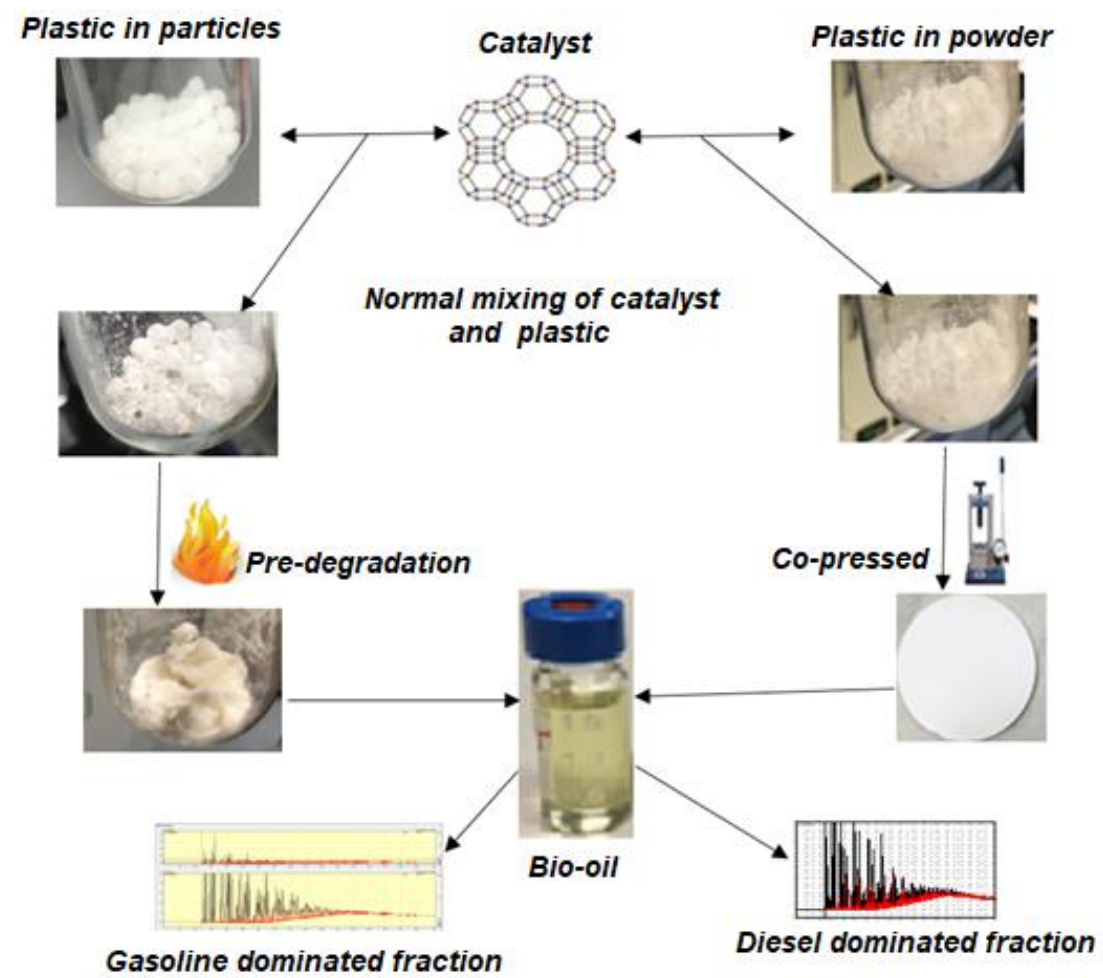

\section{Keywords}

Pre-degradation treatment,

Polyolefins,

Zeolite catalysts

Liquid characterisation

Coke characterisation 


\section{Introduction}

Polymer wastes and related materials have attracted much attention in recent years because of their potential to be converted into transportation fuels as well as raw materials for catalytic transformation into products of energetic interest and suitable for applications in petrochemical industries [1]. The use of plastics is increasing with the development of more and more useful plastics and their disposal is a big problem, as these do not biodegrade in nature for a very long time. Therefore, recycling of plastic wastes is very important from an energy point of view as well as an environmental point of view $[1,2,3,4,5]$.

Among the different method of plastic wastes recycling, direct combustion and land filling may have a huge environmental impact. Tertiary recycling by conversion of plastic wastes into fuels, chemicals or monomers represents an interesting alternative, since it could be merged into standard petrochemical or petroleum refinery industrial operations $[6,7,8,9]$. Tertiary recycling has the highest potential for a successful future commercialisation $[10,11,12,13,14]$ and can contribute significantly towards a cheaper solution to the energy crisis $[11,15,16]$. Plastics can be recycled via tertiary recycling through thermal, catalytic or combination of thermal and catalytic degradation. Pure thermal degradation of plastic wastes requires high temperatures and produces heavy products that need further processing $[2,12,13,14,16,17,18]$. The presence of catalyst reduces the process temperature as it lowers the activation energy for breaking $\mathrm{C}-\mathrm{C}$ bonds and decreases the residence time of plastics in the reactor, because of the faster rate of degradation. It also produces hydrocarbon in the motor fuel range, which eliminates the need for further upgrading process steps $[12,14,17,18,19,20,21,22,23]$.

Liquid fuel served as the most valuable product from the thermal and catalytic degradation of plastic. Gaseous products are of low value but they are useful as well, as their burning can contribute to the energy demands of the endothermic pyrolysis process. However, excess gas 
production is not desirable because of their transportation costs. Consequently, the target of a commercially viable recycling process should be an increase of the liquid product yield [12, 22, 24]. Zeolite-based catalysts have been used in catalytic degradation of polymer [13, 14,18, 19, 22], as well as silica-alumina [25], clay-based catalysts [12,18] and MCM-type mesoporous materials [26, 27]. The required properties of highly active catalysts for the pyrolysis of plastics are a large external surface area and pores at the right size, large enough for enabling secondary cracking of very large hydrocarbon molecules with fast mass transfer of reaction components, but small enough to suppress carbon deposits as well as overcracking to very small gaseous products. Many researchers have used various zeolites due to their acidity. The application of zeolites to the pyrolysis of waste plastics, however, has encountered technical problems, such as relatively high quantity of gas products and coke formation, which consequently decrease the liquid product yield. This is attributed to the very strong acidity of the zeolitic sites, which brings about severe cracking of the plastic molecules $[19,28,29]$ via enhancing of secondary reactions. Catalytic cracking over zeolite-based catalysts as an important hydrocarbon reaction suffers from deactivation from strong coking [30], resulting from the formation and retention of heavy byproducts known as coke [31]. The composition of coke depends on the nature of the reactants, time-on-stream, temperature, acid site concentration and the location of coke deposit. In most commercial processes, the cost of catalyst deactivation is very high. Hence, facilitating the catalyst stability and optimising regeneration is an important measure of controlling the activity and selectivity of the catalyst [32].

As shown in our previous studies, the performance of polymer catalytic degradation system does not depend only on the activity of the catalyst and experimental parameters. Physical process phenomena like mixing of polymer and solid catalyst played a key role in fixing the quality and quantity of the liquid and coke yields. In the present work, different types of polymer and zeolite catalyst are considered and study using different mixing regimes. 


\section{Experimental}

\subsection{Materials}

The polymers used include linear low-density polyethylene (IIdPE), low-density polyethylene (IdPE), high-density polyethylene (hdPE) and polypropylene (PP) in pellet forms provided by Vantage Polymers Ltd. They have an average particle size of $1-2 \mathrm{~mm}$ with a density of 0.928 $\mathrm{g} / \mathrm{cm}^{3}$ and an average molar mass of $117 \mathrm{~kg} / \mathrm{mol}$. Medium density polyethylene in powder form with CAS number $=9002-88-4, \mathrm{mp}=379-384 \mathrm{~K}$, density $=0.94 \mathrm{~g} / \mathrm{mol}$ at $298 \mathrm{~K}$ purchased from Sigma-Aldrich Co., Ltd UK was also used as a polymer sample. The catalysts used include HY, USY, ZSM-5 90 and ZSM-5 400 zeolites with Si/Al ratio of 2.5, 5.7, 45 and 200 respectively. All the catalyst samples are in powder form provide by Grace Gmbh with an average particle size of $1 \mu \mathrm{m}$.

\subsection{Experimental setup}

The experimental rig as shown in Fig. 1 is made-up of a semi-batch pyrex reactor with two semicircle infrared heating elements for fast heating connected to a temperature controller, mass flow controller and two condensers placed in ice baths for liquid collection. The reactor has an internal diameter of $30 \mathrm{~mm}$. The external diameter of the reactor was $35 \mathrm{~mm}$ and a total height of 150 $\mathrm{mm}$, with a capacity of $0.2 \mathrm{~L}$. The full description of the experimental procedure is in [33]. 


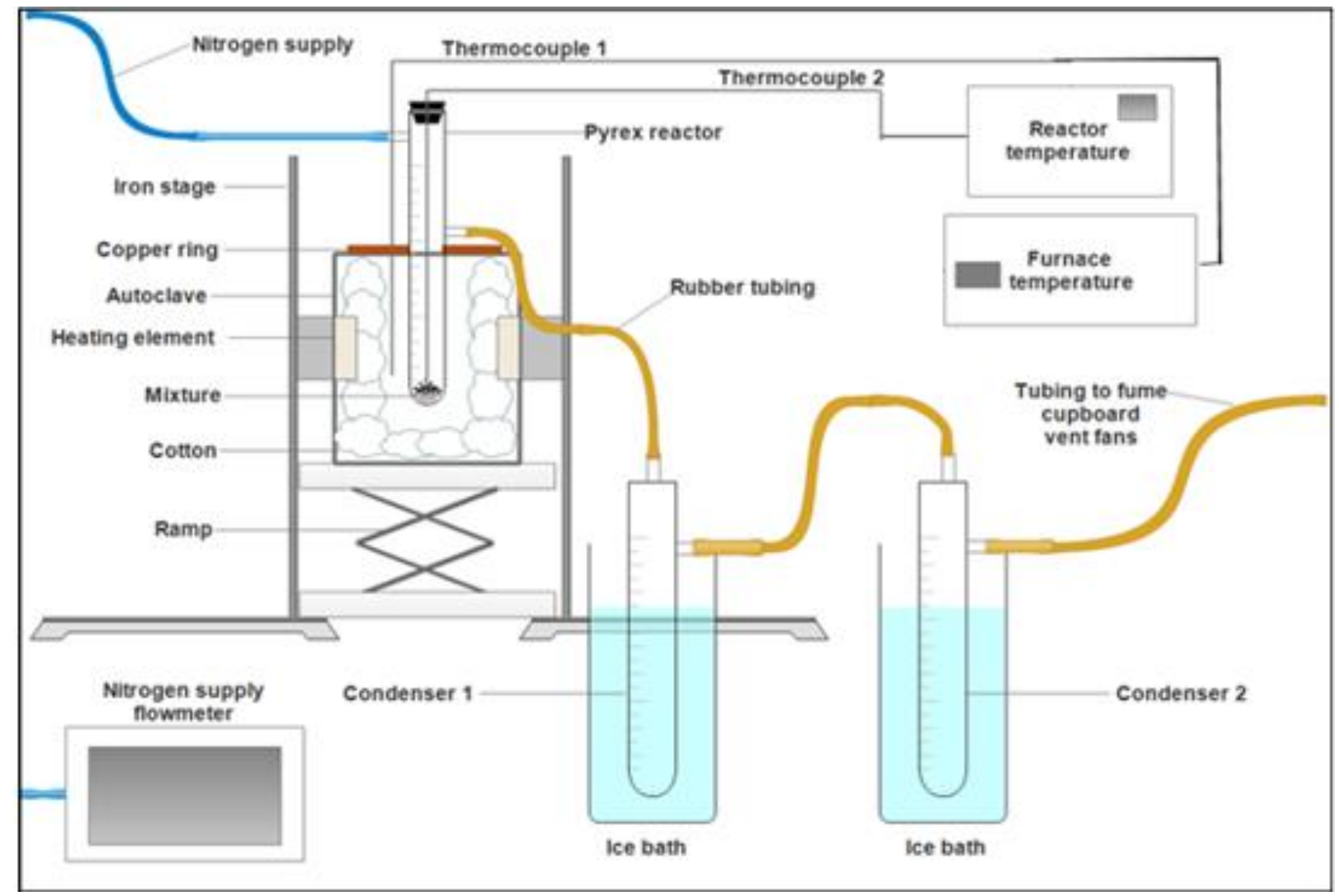

Figure 1. Schematic diagram of the laboratory semi-batch reactor system

\subsection{Experimental Calculations}

The conversion to volatile products was based on the fraction of the initial mass of polymer reacted to form volatile products.

The percentage liquid yield is the mass of the liquid collected divided by the initial amount of the polymer i.e. the fraction of the original polymer converted to the liquid products multiply by 100.

$Y_{l}=m_{l} / m_{p}{ }^{*} 100$ 
Where $Y_{l}=$ Liquid yield

$m_{l}=$ Mass of the liquid collected

$m_{p}=$ Mass of the polymer

The percentage coke yield is the mass of the coke obtained after the experiment divided by the initial amount of the polymer and represents the fraction of the original polymer converted to coke multiply by 100 .

$$
Y_{c}=m_{c} / m_{p}^{*} 100
$$

Where $Y_{c}=$ Coke yield

$m_{c}=$ Mass of the coke obtained

$m_{p}=$ Mass of the polymer

The coke concentration is the amount of coke deposited on the catalyst divided by the catalyst mass and represents the amount of coke formed per $g$ of catalyst and is estimated by TGA and converted to yield based on the catalyst amount in the reactor.

$$
C_{c}=m_{c} / m_{\text {cat }}
$$

Where $C_{c}=$ Coke concentration

$m_{c}=$ Mass of the coke deposited on the catalyst

$m_{\text {cat }}=$ Mass of the catalyst

\subsection{Liquid sample analysis}

The liquid products were analysed on a Shimadzu 2014 gas chromatograph equipped with a flame ionization detector (FID) using a non-polar Rtx-1 DHA 100m x 0.25mm x 0.50 $\mu$ m capillary column. The hydrogen flow rate was $30 \mathrm{~mL} / \mathrm{min}$ and the injector temperature was set at $543 \mathrm{~K}$. The temperature program began with a hold at $313 \mathrm{~K}$ for $10 \mathrm{~min}$ followed by a ramp of $278 \mathrm{~K} / \mathrm{min}$ to $543 \mathrm{~K}$, and a hold for another 30 min while the FID detector temperature was set at $573 \mathrm{~K}$. A 
calibration mixture of normal alkanes $\mathrm{C}_{5}-\mathrm{C}_{20}$ (standard) was run at the beginning of the analysis to assign retention time to each components as shown in the table1. The full GC procedure is available in [33].

Table 1. Retention time for various hydrocarbon groups

\begin{tabular}{ccc}
\hline Hydrocarbon group & Boiling point (K) & Retention time (min) \\
\hline $\mathrm{C}_{5} \mathrm{H}_{12}$ & 309.20 & 16.03 \\
$\mathrm{C}_{6} \mathrm{H}_{14}$ & 341.90 & 20.94 \\
$\mathrm{C}_{7} \mathrm{H}_{16}$ & 371.60 & 27.16 \\
$\mathrm{C}_{8} \mathrm{H}_{18}$ & 398.80 & 33.26 \\
$\mathrm{C}_{9} \mathrm{H}_{20}$ & 424.00 & 38.64 \\
$\mathrm{C}_{10} \mathrm{H}_{22}$ & 447.30 & 43.37 \\
$\mathrm{C}_{11} \mathrm{H}_{24}$ & 469.10 & 47.61 \\
$\mathrm{C}_{12} \mathrm{H}_{26}$ & 51.49 \\
$\mathrm{C}_{13} \mathrm{H}_{28}$ & 489.50 & 55.05 \\
$\mathrm{C}_{14} \mathrm{H}_{30}$ & 508.60 & 58.51 \\
$\mathrm{C}_{15} \mathrm{H}_{32}$ & 526.70 & 61.91 \\
$\mathrm{C}_{16} \mathrm{H}_{34}$ & 543.80 & 65.26 \\
$\mathrm{C}_{17} \mathrm{H}_{36}$ & 560.00 & 68.71 \\
$\mathrm{C}_{18} \mathrm{H}_{38}$ & 575.20 & 72.43 \\
$\mathrm{C}_{19} \mathrm{H}_{40}$ & 589.50 & 76.60 \\
$\mathrm{C}_{20} \mathrm{H}_{42}$ & 603.10 & 81.45 \\
\hline
\end{tabular}

\subsection{Thermal gravimetric analysis}

The TGA measurements with Perkin Elmer Pyris TGA instrument was done at NICE (Nature Inspired Chemical Engineering) lab facility University College London. In a typical run ca.10 mg of the polymer and/ coked catalyst was heated to $473 \mathrm{~K}$ at a rate of $10 \mathrm{~K} / \mathrm{min}$ and was maintained for 30 min under nitrogen flow $\left(30 \mathrm{~mL}_{N} / \mathrm{min}\right)$ to remove the adsorbed water and any reaction mixture components. After this period, the temperature was raised to $1073 \mathrm{~K}$ at a rate of $5 \mathrm{~K} / \mathrm{min}$ and kept constant for $30 \mathrm{~min}$ at the final temperature. The full GC procedure is available in our previous paper [33]. 


\subsubsection{Coke Characterisation and Calculation}

The coke classification as shown in Fig. 2 is simple and specific method using the TGA of coked catalyst. This characterisation provides information about the character of coke components, more specifically their volatility.

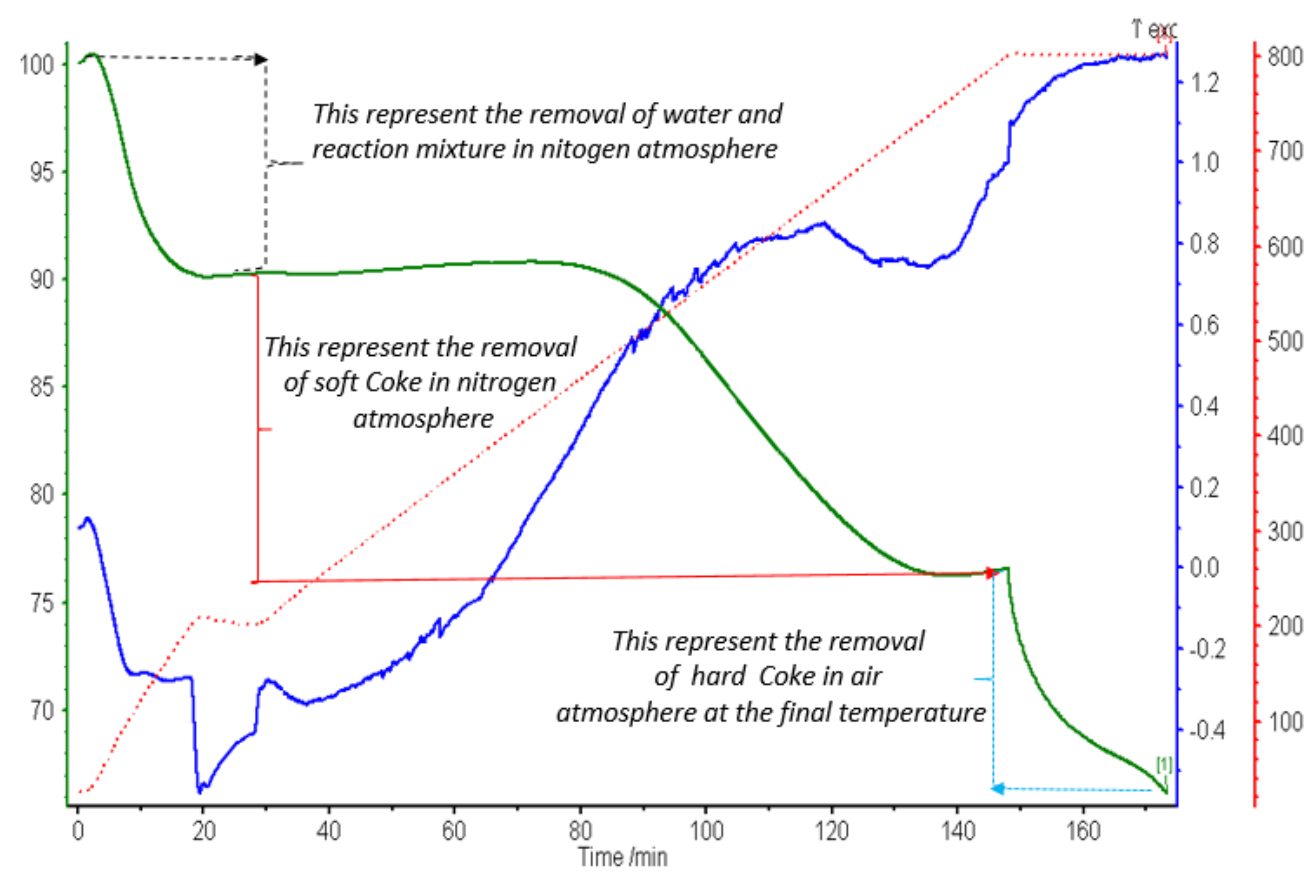

Figure 2. TGA of coked sample containing the description of coke characterisation

As presented in figure 2 the procedure consists of removal of water and reaction mixture from room temperature to $473 \mathrm{~K}$. The Coke components were classified into soft coke and hard coke. The soft coke was removed from $473 \mathrm{~K}$ to $1073 \mathrm{~K}$ through volatilisation in inert nitrogen while the hard coke remains on the catalyst even at high temperature $(1073 \mathrm{~K})$ and was removed by burning i.e. by switching the atmosphere from nitrogen to air as demonstrated in figure 2 .

$$
\text { Soft coke }(\%)=\frac{\text { Mass of soft coke }}{\text { Total mass of coke }} * 100
$$




$$
\text { Hard coke }(\%)=\frac{\text { Mass of hard coke }}{\text { Total mass of coke }} * 100
$$

Where Mass of soft coke is the total weight of the coke removed in nitrogen atmosphere from $473 \mathrm{~K}$ to $1073 \mathrm{~K}$ and Mass of hard coke is the total weight of the coke removed in air atmosphere at the final temperature $(1073 \mathrm{~K})$ while Total mass of coke correspond to the total weight of soft and hard coke.

\subsection{Pre-degradation treatment process}

Different types of pre-degradation treatment methods were employed in this research work in order to provide optimal contact between the polymer and catalyst which include Pre-degradation treatment and co-pressing method.

As stated in section (2.1) the polymer samples, which include IIPE, IdPE, hdPE and PP were in particles forms while only mdPE is in powder form. The contact between the polymer in particles forms and the catalyst in powder form was not efficient and therefore pre-degradation treatment method was used to promote the contact between the polymer and catalyst. On the other hand, for mdPE where both the polymer and catalyst are in powder form, pre-degradation treatment and co-pressing methods were used to provide intimate contact between the polymer and catalyst.

\subsubsection{Pre-degradation treatment}

Pre-degradation treatment involves heating of the mixture of polymer and catalyst to $393-453 \mathrm{~K}$ for 10 minutes, a temperature at which the polymer had melted and in presence of catalyst solid state polymer chain reactions had taken place but no volatile products formation [14]. As the polymer melted, the mixture was stirred constantly for about 1 min resulting in an intimate contact 
between the polymer and catalyst, thereby enhancing the catalyst activity. A schematic presentation of this process is presented under the graphical abstract.

\subsubsection{Co-pressing Method}

In co-pressing method, the powder polymer and catalyst were mixed thoroughly with a spatula as in a normal mixing. After this stage, the mixture was placed on a hydraulic press and pressed for $5 \mathrm{~min}$ at a weight of 3 tons for 5 times, so as to produce intimate contact between the polymer and catalyst as shown in figure 3 below. The disc containing polymer and catalyst was crushed gently using hand to produce smaller pellets of sizes that could be placed in the reactor.

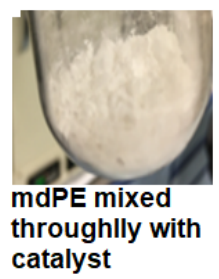

catalyst

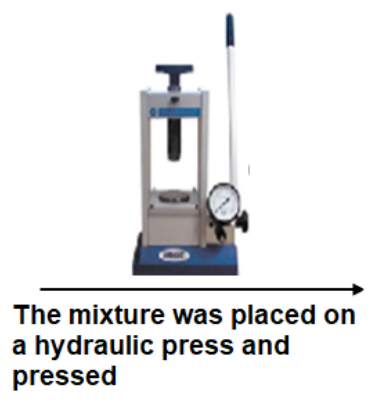

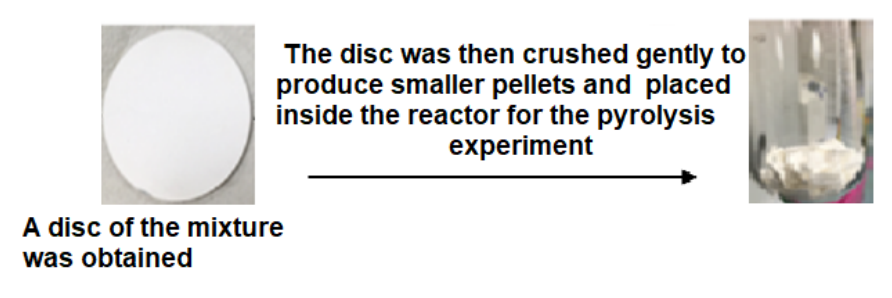

Figure 3. Schematic presentation of polymer/catalyst co-pressing method 


\section{Results and Discussion}

3.1 Experimental results from TGA of polyethylene. Influence of pre-degradation treatment on the degradation pattern of polyethylene

To evaluate the effect of pre-degradation treatment on the pyrolysis pattern of polymer, TGA measurements of two different types of polyethylene- mdPE (powder) and IldPE (particles)- were conducted as presented in figure 4.

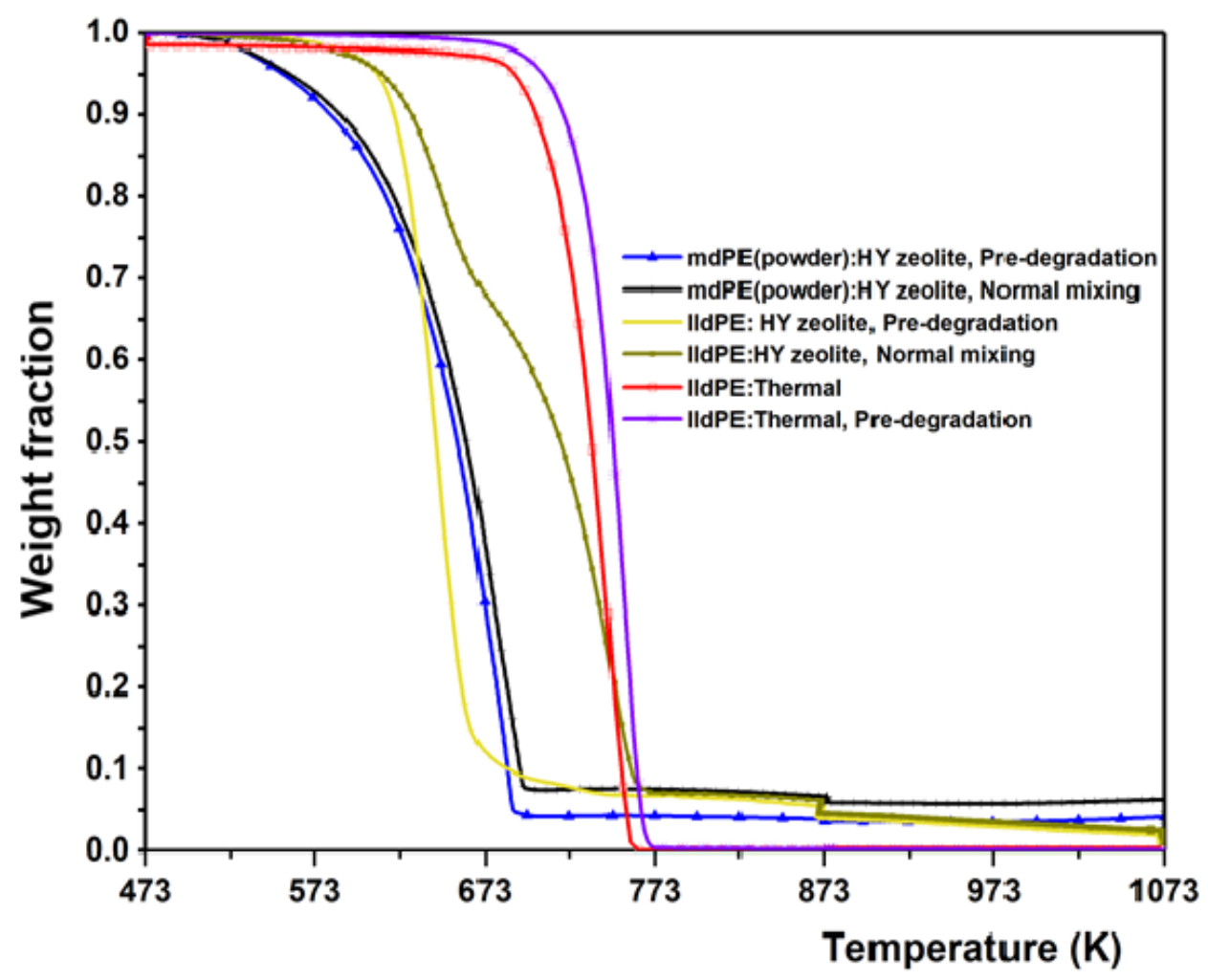

Figure 4. TGA of $\mathrm{mdPE}$ and IIdPE thermal and catalytic degradation using pre-degradation treatment; polyethylene mass fraction against temperature 
Figure 4 consists of the TGA results for the thermal and catalytic degradation of mdPE and IldPE using normal mixing and pre-degradation treatment. In our recent publication we have shown that, pre-degradation treatment was very effective in improving the catalytic degradation of polymer especially lowering of the pyrolysis temperature, making it the most appropriate method for catalytic degradation of polymer particles especially at low reaction temperature. The present study looked at broader aspects by considering different mixing states including the powderpowder case where an intimate contact can be achieved using an ordinary mixing with spatula. As shown in figure 4, mdPE was used to demonstrate the influence of pre-degradation treatment where both polymer and catalyst are in powder form and that was compared alongside with IldPE degradation where the mixing situation is particles-powder.

As expected, the interaction between polyethylene and catalyst was higher with powderpowder than particles-powder interaction hence the optimal utilization of the catalyst activity. As shown in figure 4, the degradation of mdPE using normal mixing started at $520 \mathrm{~K}$ with a peak at about $700 \mathrm{~K}$ while with pre-degradation treatment it started at $516 \mathrm{~K}$ with a peak conversion attained at $688 \mathrm{~K}$. The degradation pattern shifted to slightly lower temperatures with predegradation treatment compared to the normal mixing, even though, much less significant difference than with IIdPE, (particles-powder) interaction. The latter achieved higher conversion with lower coke content predominantly soft coke which is very interesting in hydrocarbon conversion reactions. As presented in figure 4, pre-degradation treatment has a slight negative effect on thermal pyrolysis degradation. It shifted the degradation pattern to slightly higher temperatures. However, with catalytic degradation clearly the difference was due to the nature of the interaction between the polymer and catalyst.

There is a clear difference between the degradation patterns of mdPE and IIdPE as shown in figure 4. A shoulder existed in IIPE degradation that does not appear in mdPE degradation. This shoulder revealed that particles-powder interaction as in IIPE is not pure catalytic 
degradation due to the poor contact between the catalyst and IIdPE and part of the IIdPE was converted through thermal degradation.

Similar studies and results were reported in the literature. Among these is the investigation of the effect of contact between polymer and catalyst by Marcilla et al. [34]. The results from their work showed a better contact between the polymer and catalyst accelerates the activity of the catalyst, reduces the heavy fractions and leads to higher volatile yields than thermal degradation. Abbas-Abadi et al. [35] reported the effect of stirring on hydrocarbon products of LLDPE catalytic degradation. Findings from their study shows that in catalytic pyrolysis, stirring of the melted polymer greatly accelerates the heat transfer process and help the process for better energy saving and temperature homogeneity and the catalyst can have better operation on the products. Caldeira et al. [36] adopted a procedure of thermal homogenization that is similar to predegradation treatment. They carried out TGA analysis of catalytic degradation of IdPE with $\mathrm{Y}$ zeolite using thermal homogenization procedure to improve the process. Their TGA results shows that $\mathrm{Y}$ zeolite exhibited only one mass loss event for the thermal homogenization and two mass loss events without thermal homogenization. This fact indicates that the Thermal homogenization procedure supplied different reaction mechanisms, with lower coke formation and generation of lower molecular mass products.

As suggested by Marcilla et al. [37] in normal mixing of IldPE with the catalyst, the available contact permits the degradation of a fraction of the IldPE at lower temperatures through catalytic pathway, whereas, the rest of the polymer were decomposed by thermal non-catalytic cracking at higher temperatures. Based on results obtained from this study and references cited, the contacts in powder-powder and particles-powder forms are not coequal to the pre-degradation treatment. Pre-degradation treatment provides a better way that accommodated the polymer macromolecules on the surface of the catalyst, permitting the degradation to proceed faster with higher conversion, more volatiles and lower coke formation. 


\subsection{Results from polymer pyrolysis reactor experiments}

\subsubsection{Effect of pre-degradation treatment on the product yields from catalytic degradation of polypropylene with different catalysts}

Further developments in the process of plastics recovery have included the use of catalysts. These allowed different ways of producing speciality chemicals and maximising products selectivity to gasoline range fractions [38]. In most applications, catalysts aimed to reduce the required reaction temperature, improve the yield of volatile products and provide selectivity in the product distributions, thus enhancing the economic potential of the process [39, 40, 41]. Zeolite catalysts can catalyse different types of chemical reactions due to their shape selectivity, framework structure and the variation in their acid strength and content [42]. Zeolite catalysts exist with different pore window sizes ranging from $5 \AA$ to $12 \AA$ [43], resulting into a molecular sieving effect, excluding certain reactant molecules based on their size relative to the zeolite pore window size [44]. Similarly, the formation of products larger than the pore size of the zeolite were restricted $[42,43,44]$. In order to explore these different properties associated with zeolites catalysts, catalytic pyrolysis of polypropylene was carried out using different zeolite catalysts and the results of liquid and coke yields are presented in figure 5 below.
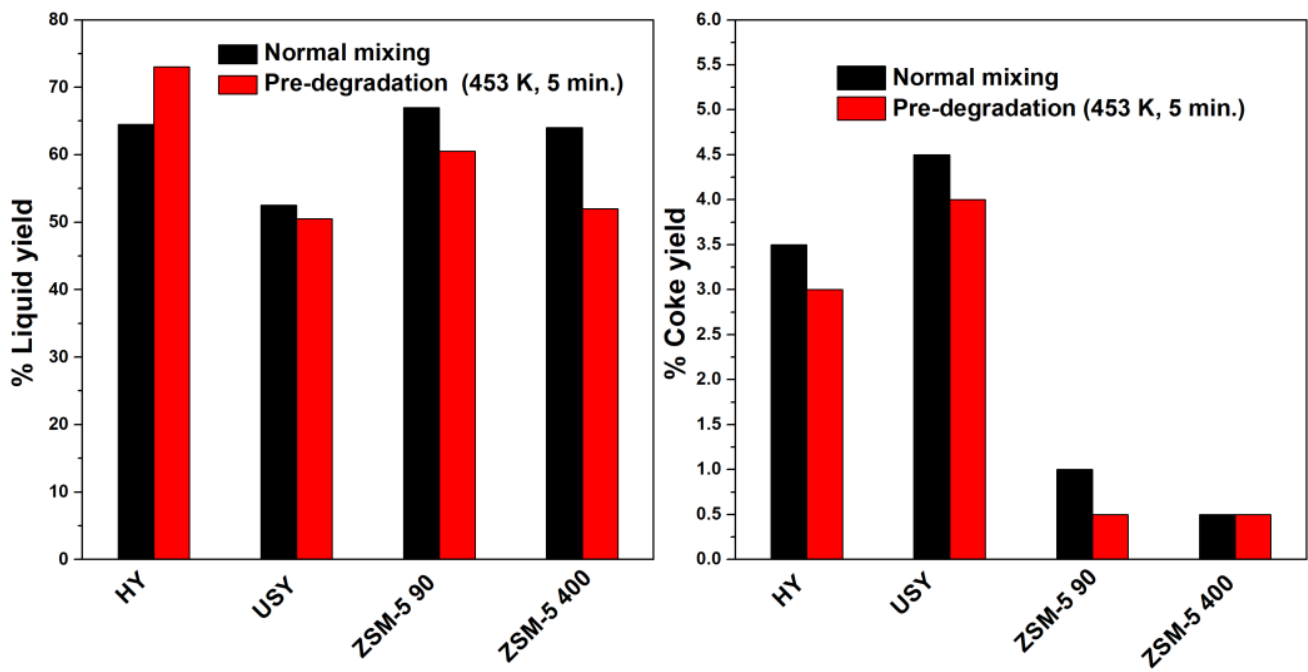

Figure 5. Comparison of the liquid and coke yields for catalytic degradation of PP with different catalysts using normal mixing and pre-degradation treatment (pyrolysis temperature $=723 \mathrm{~K}$, Flow rate $10 \mathrm{~mL} / \mathrm{min}$ ) 
HY catalyst produced $64.5 \%$ and $73.0 \%$ of liquid yields and $3.5 \%$ and $3.0 \%$ coke yields using normal mixing and pre-degradation treatment respectively. For USY catalyst, the liquid yields were $52.5 \%$ and $50.5 \%$ while the coke yields were $4.5 \%$ and $4.0 \%$ respectively. Using the normal mixing and pre-degradation treatment ZSM-5 90 catalyst produced $67.0 \%$ and $60.5 \%$ of liquid yields with $1.0 \%$ and $0.5 \%$ of coke yields respectively while ZSM- $540064.0 \%$ and $52.0 \%$ of liquid yields and the same coke yield of $0.5 \%$.

Looking at the overall results, using normal mixing, the liquid yields obtained were of the order ZSM-5 $90>$ HY > ZSM-5 $400>$ USY. The lowest liquid yield and highest coke yield was produced by USY and this was consistent with the structures of the zeolites and their acidities [22, 45, 46]. In general, ZSM-5 catalysts produced lower coke content compared to the other zeolite catalysts. The pattern of the product yields varies using pre-degradation treatment with low coke yields across all the catalysts and HY catalyst producing the highest liquid yield. For ZSM-5 90, ZSM-5 400 and USY there is a decrease in the liquid yields due to their higher acidity. Higher catalyst acidity enhances cracking reactions and promotes overcracking leading to lower liquid yield. HY and USY zeolites have larger surface areas and pore sizes than ZSM-5 catalysts [22, 47, 48, 49]. The presence of large cavities in $Y$ type zeolites enables the polymer macromolecules and large initial fragments from the primary reactions to diffuse readily into the internal acid sites, making the cracking reactions over HY and USY more efficient than ZSM-5. Hence the severity of coking with USY and HY catalysts is higher than with ZSM-5 catalysts [45]. The ZSM- 5 catalyst with high $\mathrm{SiO}_{2} / \mathrm{Al}_{2} \mathrm{O}_{3}$ produced highest liquid and coke yields. This implies the advantage of strong acid sites in polymer degradation especially for catalysts with small pore structure.

HY catalyst was very active at low temperature and effective in the initial degradation of polymer due to the higher acid site density. At higher temperatures, HY suffered severe deactivation leading to poor performance. Using pre-degradation treatment this disadvantage with HY zeolite has been overcome as the transformation took place at lower temperatures avoiding 
the structure collapse at extreme experimental conditions. On the other hand, USY has higher thermal stability and strong acid sites than HY zeolite with extra-framework aluminium that created mesoporous sites [22, 45, 46, 47, 48, 49]. Therefore, USY zeolite produced lower liquid yield and higher coke content than other zeolite catalysts used. Lerici et al. [50] studied thermocatalytic degradation of polypropylene (PP) using the HY zeolite in a batch reactor at $773 \mathrm{~K}$. They reported that thermal cracking of polyolefins produced waxes and the use of catalyst yielded higher percentages of gaseous products with liquid product yields of $42 \%$ wt $\%$ and $10 \mathrm{wt} \%$ residues. The higher amount of gas and coke yields are due the experimental conditions used i.e. reaction temperature $(773 \mathrm{~K})$, polymer to catalyst ratio $(2: 1)$, reaction time $(43.75 \mathrm{~min})$ and nitrogen flow (25 mL/min) when compared with the present work. In a similar work, Kassargy et al. [46] conducted thermal and catalytic pyrolysis of polypropylene over USY zeolite in a batch reactor at $673 \mathrm{~K}$. The thermal degradation gave $85.5 \mathrm{wt}$. \% of liquid yield while in the presence of USY catalyst 82 wt. \% of liquid yield and 1.24 wt. \% of coke yield were produced. The differences in the liquid and coke yields with the present study are based on the acidity of the catalyst $(\mathrm{Si} / \mathrm{Al}=7.5)$, plastic to catalyst ratio $(10: 1)$ as well as the nitrogen flow rate used in the two studies.

\subsubsection{Effect of pre-degradation treatment on the product yields from catalytic degradation of different types of polymer}

Beside the zeolite structure, polymer structure also determines the activity of a zeolite catalyst in catalytic cracking of polymers. The polymer chain ends are able to penetrate into the zeolite pores, reaching acid sites located therein and increasing the activity [45]. Branched polymers such as IdPE possessed greater relative activity with zeolites of small pore size than nonbranched polymers, while there are no differences in the relative activity of branched and nonbranched polymers if the zeolite pores are large enough for the main chain to penetrate [51]. 
Catalytic pyrolysis experiments were conducted with different polymers to relate the polymer structure to the zeolite activity as shown in figure 6.
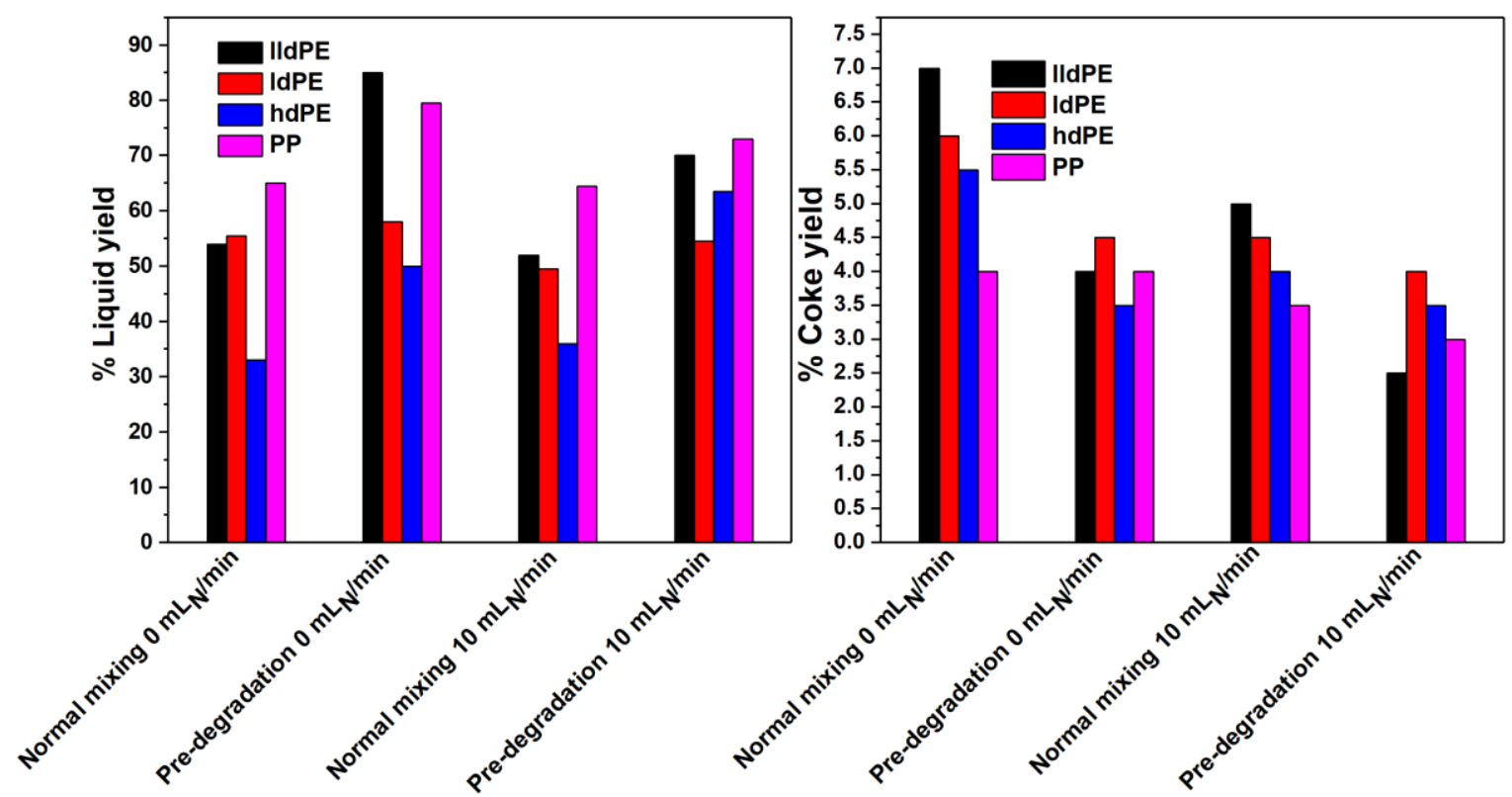

Figure 6. Percentage liquid and coke yields for catalytic pyrolysis of different polymers with HY catalyst using normal mixing and pre-degradation treatment with and without $\mathrm{N}_{2}$ flow (pyrolysis temperature = 723 K; polymer, $2 g$ : catalyst, $0.5 g$ )

The increase in flow rate as shown in figure 6 has affected the product yields especially the coke yield but the changes due to the pre-degradation treatment are higher. Pre-degradation treatment leads to increased liquid yields and decreased coke yields in all cases. With the normal mixing, the liquid yields from IIdPE decrease from $54.0 \%$ to $52.0 \%$ as the $\mathrm{N}_{2}$ flow rate increased from 0 to $10 \mathrm{~mL} / \mathrm{min}$ while the coke yields also decreased from $7.0 \%$ to $5.0 \%$. The same behavior was exhibited by IdPE where the liquid yield changed from $55.5 \%$ to $49.5 \%$ and the coke yield decreased from $6.0 \%$ to $4.5 \%$. For hdPE the liquid yield increased from $33.0 \%$ to $36.0 \%$ while the coke yield decreased from $5.5 \%$ to $4.0 \%$ as the flow rate was increased from 0 to $10 \mathrm{~mL} / \mathrm{min}$. 
PP showed similar behaviour with IIPE and IdPE as the liquid yields decreased from $65.0 \%$ to $64.5 \%$ and the coke yields decreases from $4.0 \%$ to $3.5 \%$.

As the flow rate changed from 0 to $10 \mathrm{~mL}_{N} / \mathrm{min}$ pre-degradation treatment showed similar pattern in the product yields as with the normal mixing but the magnitude of the changes was different. For IIdPE the liquid yield decreased from $85.0 \%$ to $70.0 \%$ and the coke yield decreased $4.0 \%$ to $2.5 \%$. For IdPE the liquid yield decreases from $58.0 \%$ to $54.5 \%$ while the coke yield decreases from $4.5 \%$ to $4.0 \%$. The liquid yield increased with hdPE from $50.0 \%$ to $63.5 \%$ while the coke yield remained the same at $3.5 \%$. For PP, the liquid yield decreased from $79.5 \%$ to $73.0 \%$ and the coke yield decreased from $4.0 \%$ to $3.0 \%$.

Based on the polymer used, IldPE, IdPE and PP showed similar behavior where by the liquid yields decreased with increase in the $\mathrm{N}_{2}$ flow rate using both normal mixing and predegradation treatment. Inert flow rate is very important parameter as it can influence the residence time of primary products in the reactor and affect secondary reactions, overcracking and coke formation respectively. It also facilitates a better heat transfer in the system [33]. In the case of normal mixing, the increase in the carrier gas enhances the reaction system. It reduces the residence time of primary products, decreases secondary reactions hence resulting into higher amounts of liquid products. On the other hand, high flow rate enhances the evaporation of liquid products into gaseous fractions in the condenser after the reactor that caused the decrease in the liquid and coke yields respectively. Gulab et al. [52] reported similar effect of carrier gas in their investigation on the effect of various process variables in the performance of catalytic systems in polymer degradation. Similar reasons accounted for the decrease in the liquid and coke yields using the pre-degradation treatment. In addition, pre-degradation treatment produces higher conversion and volatile fractions solely due to the intimate contact between the polymer and catalyst. For hdPE, due it is structure, the coke yields decreased while the liquid yields increased with more heavier fractions and fewer lighter fractions. Based on the overall results, IldPE and 
hdPE show wide differences between normal mixing and pre-degradation treatment. For IldPE it produces higher coke content which leads to the decrease in the conversion and subsequently improved with the pre-degradation treatment. For hdPE it produces heavier fractions with very low conversion and these were turn around with the pre-degradation treatment which produces higher liquid yield and lower coke yields.

Manos et al. [22] carried out catalytic degradation of hdPE with $\mathrm{Y}$ zeolite $(\mathrm{Si} / \mathrm{Al}=2.5)$ in a semi-batch reactor at a final temperature of $633 \mathrm{~K}$ and flow rate of $50 \mathrm{~mL} / \mathrm{min}$. They obtained a liquid yield of $41.0 \%$ and $13.0 \%$ coke yield. These are similar to the values reported in figure 6 by considering the differences in the flow rate, polymer to catalyst ratio $(2: 1)$ and the contact method used (powder-powder) interaction. The higher amount of coke reported by the latter study is connected to the higher polymer to catalyst ratio used which double the amount of catalyst used by the present study while the mass of the polymer remain constant.

\subsubsection{Effect of pre-degradation treatment on the product yields from catalytic degradation of IIdPE at different reaction temperature}

The product yield of pyrolysis system depends largely on the operational reaction temperature. The pyrolysis reaction time decreased with increase in temperature. High temperature supports the easy cleavage of bond and thus speeds up the reaction and lowers the reaction time [53]. The increased in temperature supplied more energy to the polymer to weaken its chain structure, thus more polymer chains were cracked [54]. The effect of reaction temperature on the product yields of catalytic degradation of IldPE was studied using two similar but counterpoise catalysts and the results are presented in figure 7 using different methods. 
Using normal mixing with HY catalyst at lower temperature of $673 \mathrm{~K}$, lower liquid yield and higher coke/unconverted polymer were obtained with $27.5 \%$ and $6.0 \%$ for liquid and coke yields respectively. Using pre-degradation treatment at the same reaction temperature the liquid yield has increased to $56.0 \%$ and coke yield decreased to $3.5 \%$ respectively.
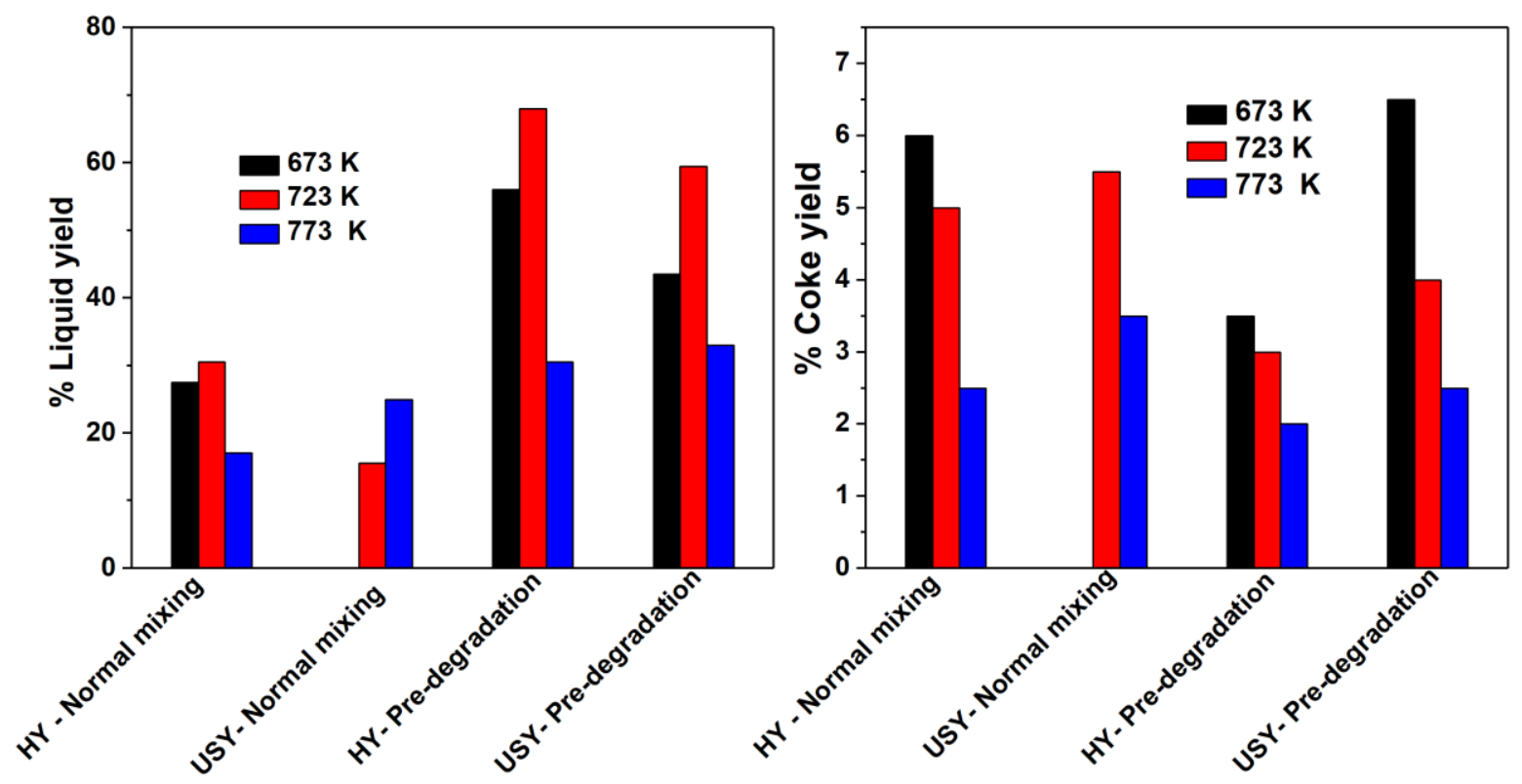

Figure 7. Percentage liquid and coke yields for catalytic pyrolysis of IIdPE using normal mixing and predegradation treatment at different reaction temperature $\left(\mathrm{N}_{2}\right.$ flow rate $=80 \mathrm{~mL} / \mathrm{min}$; polymer, $2 \mathrm{~g}$ : catalyst, $0.5 g$ )

USY catalyst at the same reaction temperature produced lower liquid yield of $43.5 \%$ and higher amount of $6.5 \%$ coke yield. The medium temperature of $723 \mathrm{~K}$ as used in this study represents the temperature for optimum liquid yields using $\mathrm{HY}$ catalyst with $30.5 \%$ and $68.0 \%$ for normal mixing and pre-degradation treatment. At this temperature, the coke yield decreased from $5.0 \%$ to $3.0 \%$ with $\mathrm{HY}$ zeolite and $5.5 \%$ to $4.0 \%$ with USY catalyst for normal mixing and predegradation treatment respectively. At $723 \mathrm{~K}$, USY catalyst produces a liquid yield of $15.5 \%$ using 
normal mixing which increased to $59.5 \%$ using pre-degradation treatment the latter representing the optimal liquid yield with USY catalyst. At $773 \mathrm{~K}$, the liquid yield with HY catalyst decreased to $17.0 \%$ and $30.5 \%$ while the coke yields also decreased to $2.5 \%$ and $2.0 \%$ for normal mixing and pre-degradation treatment respectively. For USY catalyst, at $773 \mathrm{~K}$ the liquid yield increased to $25.0 \%$ using normal mixing and decreased to $33.0 \%$ using pre-degradation treatment while the coke yields decreased to $3.5 \%$ and $2.5 \%$ for normal mixing and pre-degradation treatment respectively.

USY catalyst has better performance at higher temperatures while HY catalyst displayed good performance at moderate temperature, obviously due to their structural differences. USY is hydrothermally stable at higher temperatures while HY experienced structural damage at higher temperatures resulting in pyrolysis taking place predominantly via non-catalytic thermal cracking. Overall, pre-degradation treatment has improved the quantity of the liquid yields and decreased the coke content at all temperatures but even more at lower temperatures. The results are very impressive and promising in terms of commercialization and sustainability of the process, being the most affordable way to produce higher liquid yields and retain the activity of the catalyst over long period.

Abbas-Abadi et al. [35] show that the reaction time of catalytic pyrolysis of IldPE decreases remarkably when the temperature increases from 693 to $783 \mathrm{~K}$ while the formation of condensed hydrocarbons shows a maximum peak at $723 \mathrm{~K}$. In a similar work, Wong et al. [54] reported that the increase in temperature led to further cracking of oligomers to form smaller hydrocarbons that existed as gaseous compounds decreasing the liquid yield. Miskolczi et al. [55] noticed that less coke was deposited on the catalyst surface, when higher temperature was used in the presence of $\mathrm{HY}$ zeolite. The increase in the temperature from 698 to $758 \mathrm{~K}$ decreases the coke yield from $20.5 \%$ to $18.2 \%$ respectively. In a different work, Kumar and Singh [53] showed that the recovery of condensable fraction was very low at low temperature of $673 \mathrm{~K}$ and increased with gradual 
increase of temperature. Similarly, at high temperatures the liquid yield decreases due to the volatilization of higher molecular-weight products before undergoing further cracking and more non-condensable gaseous/volatile fractions due to stronger cracking. These studies are in line with the findings of this study. There is always a temperature peak for the liquid yield.

\subsection{Liquid Product Characterisation}

The chromatographic separation of the liquid product mixture was according to the volatility/boiling point of the components using a non-polar capillary column with the use of a calibration mixture of normal alkanes with carbon number $\mathrm{C}_{5}$ to $\mathrm{C}_{20}$. Besides the full detailed boiling point distribution, the boiling point ranges are grouped into three fractions, light, middle and heavy fractions, for better overview of the trends. The groups were assigned continuously based on the retention time of the liquid components. The light fraction includes the components in the boiling point range from $\mathrm{C}_{5}-\mathrm{C}_{9}(309.10 \mathrm{~K}-424.00 \mathrm{~K})$. The middle fraction includes the components from $\mathrm{C}_{9}-\mathrm{C}_{14}(424.00 \mathrm{~K}-526.70 \mathrm{~K})$. The heavy fraction includes the components from $\mathrm{C}_{14}-\mathrm{C}_{20}(526.70 \mathrm{~K}-617.00 \mathrm{~K})$. In addition to these fractions, there are another two fractions. The first of those, named $\left(-C_{5}\right)$, comprises of hydrocarbons lighter than $C_{5}$, i.e. compounds up to the retention time of normal pentane $\left(\mathrm{C}_{5}\right)$, while the other one, named $\left(\mathrm{C}_{20^{-}}\right)$, comprises of components with retention time higher than $\mathrm{C}_{20}$, predominantly waxes products associated with thermal cracking. Due to their nature, the amounts of these two additional fractions are generally smaller than those of the three main fractions. As zeolites have high cracking activity leading to higher amounts of gases and very few heavy liquid products, the $\left(\mathrm{C}_{20^{-}}\right)$fraction is usually considerably smaller than $\left(-\mathrm{C}_{5}\right)$. In the following figures we present the liquid product distribution results both ways, detailed all boiling point fractions as well as compressed distribution. 


\subsubsection{Effect of pre-degradation treatment on the product distribution from catalytic pyrolysis of different polymer}

Figure 8 consists of the product distribution from catalytic pyrolysis of IldPE, IdPE, hdPE and PP with HY catalyst using normal mixing and pre-degradation treatment. These results reveal the extent to which pre-degradation treatment affected polymer with different structures. As shown in figure 8 , the product distribution shows a peak in the light fraction and more specifically in $\mathrm{C}_{5}-\mathrm{C}_{6}$ with continuous decline up to high carbon numbers, heavier fractions. The pattern of the product distribution is similar across all the polymers with the highest carbon atoms distribution occurred between $\mathrm{C}_{5}-\mathrm{C}_{12}$. Based on hydrocarbon fraction groups, $\mathrm{C}_{5}-\mathrm{C}_{9}$ has the highest percentage for all the polymers and most of the product distributions are within the gasoline range fraction. For individual polymers, IIPE with normal mixing has a peak at $-\mathrm{C}_{5}$ and $\mathrm{C}_{5}-\mathrm{C}_{6}$ while with predegradation treatment the peak distribution shifted to $C_{7}-C_{8}, C_{8}-C_{9}--C_{11}-C_{12}$. The product distribution normalized at $\mathrm{C}_{6}-\mathrm{C}_{7}$ for the two mixing methods. Based on the hydrocarbon fraction groups, there is no significant difference in the product distribution between the two mixing methods.

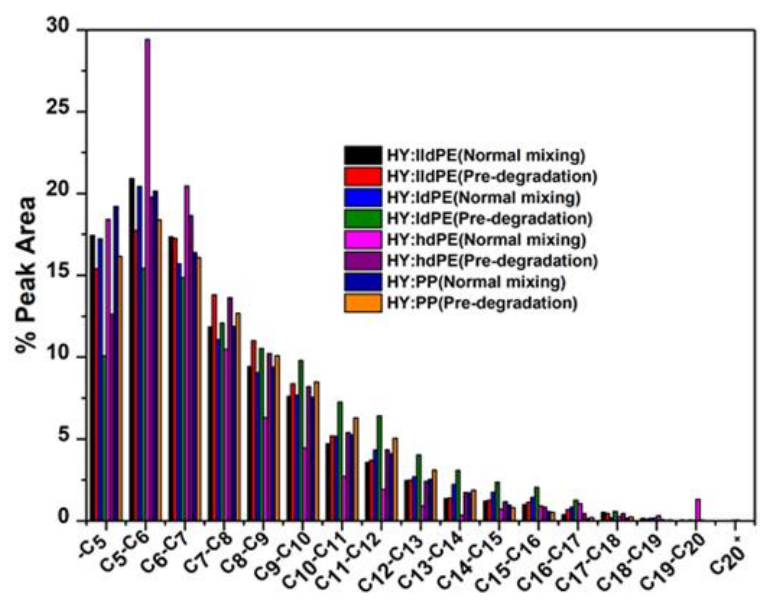

Carbon atoms distribution groups

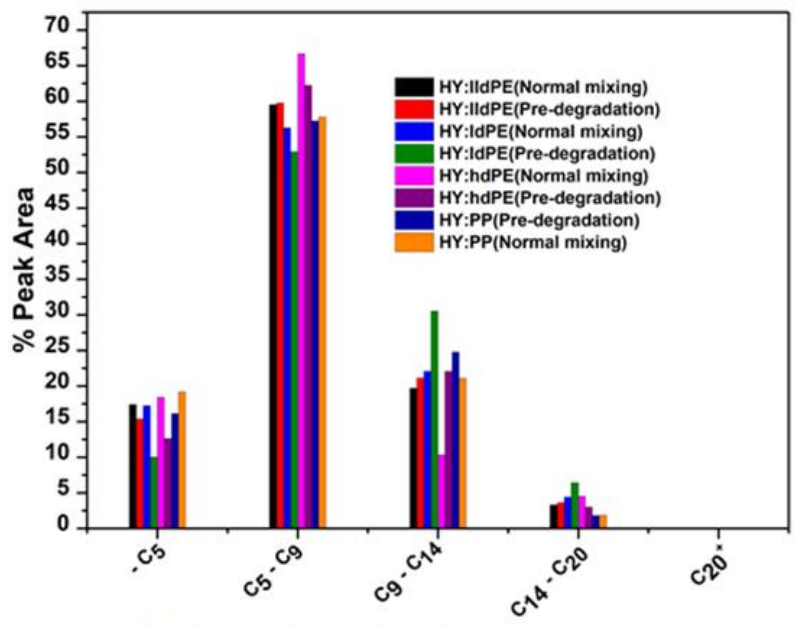

Hydrocarbon fraction groups 
Figure 8• Products distribution from catalytic pyrolysis of different polymers using different mixing method ( $\mathrm{N}_{2}$ flow rate $=10 \mathrm{~mL}_{N} / \mathrm{min}$; polymer, $2 \mathrm{~g}$ : catalyst, $0.5 \mathrm{~g}$; reaction temperature $=723 \mathrm{~K}$ ) based on the carbon atom groups and hydrocarbon fraction groups

For IdPE the pattern is similar to the product distribution of IIdPE but there is a wider difference between the two mixing methods. Normal mixing has the lightest carbon atoms distribution that extended up to $\mathrm{C}_{6}-\mathrm{C}_{7}$. After this point, the peak distribution shifted in the predegradation treatment from $\mathrm{C}_{7}-\mathrm{C}_{8}$ up to $\mathrm{C}_{17}-\mathrm{C}_{18}$. Based on the hydrocarbon fraction groups, the product distribution is better with normal mixing at $-\mathrm{C}_{5}$ and $\mathrm{C}_{5}-\mathrm{C}_{9}$ while with pre-degradation treatment performed better at $\mathrm{C}_{9}-\mathrm{C}_{14}$ and $\mathrm{C}_{14}-\mathrm{C}_{20}$.

For hdPE the product distribution is very similar to IdPE but the difference between the two methods is wider and it has the highest percentage of $C_{5}-C_{6}$ and $C_{6}-C_{7}$. As with other polymers, normal mixing showed maximum percentage of the lighter carbon atoms while pre-degradation treatment has the maximum percentage of $\mathrm{C}_{7}-\mathrm{C}_{8}--\mathrm{C}_{14}-\mathrm{C}_{15}$. In terms of the hydrocarbon fraction groups, hdPE has the highest amount of $\mathrm{C}_{5}-\mathrm{C}_{9}$ with the widest difference between the two methods occurring at $\mathrm{C}_{9}-\mathrm{C}_{14}$. The product distribution with PP showed no noticeable difference between the two methods except at few places and the pattern is closer to the product distribution of IldPE. It has the highest percentage of $\left(-\mathrm{C}_{5}\right)$ carbon atom using normal mixing which is the major difference with pre-degradation treatment across all the carbon atoms. The product distribution for $\mathrm{PP}$ at $\mathrm{C}_{5}-\mathrm{C}_{9}$ and $\mathrm{C}_{14}-\mathrm{C}_{20}$ hydrocarbon fractions showed similar percentage for all the methods. The lightest fraction $-\mathrm{C}_{5}$ was favoured by normal mixing while pre-degradation treatment was better for $\mathrm{C}_{9}-\mathrm{C}_{14}$ fraction.

Muhammad et al. [33] investigated the boiling point distribution from catalytic degradation of HY zeolite with IIdPE using normal mixing and pre-degradation treatment at different temperatures and holding times. Normal mixing showed maximum percentage of lighter fractions with a peak at $\mathrm{C}_{6}$ while for pre-degradation treatment, the peak shifted to $\mathrm{C}_{7}$. Pre-degradation 
treatment at higher temperatures shows a maximum at $\mathrm{C}_{8}-\mathrm{C}_{10}$ while pre-degradation treatment at lower temperatures is similar to normal mixing. These results are in line with the results presented in figure 8 where pre-degradation treatment maximized the gasoline fraction $\mathrm{C}_{8}-\mathrm{C}_{12}$ due to the intimate contact between the polymer and catalyst. In another study. Manos et al. [22] reported the product distribution of the catalytic degradation of high-density polyethylene on different zeolites. The product distribution with $\mathrm{Y}$ zeolite showed a peak at $\mathrm{C}_{8}$ and the percentage of the heavier alkanes was significantly lower. In the latter study, the contact between the polymer and catalyst was powder-powder and therefore the peak they reported is in between the normal mixing and pre-degradation treatment.

Lerici et al. [50] studied the thermocatalytic degradation of polyethylene of high and low density, (hdPE, IdPE), polypropylene (PP) and polyestyrene (PS) with HY zeolite in a batch reactor at $773 \mathrm{~K}$. Regarding the product distribution, polyolefins yielded similar amounts of the $\mathrm{C}_{5}-\mathrm{C}_{6}$ fraction. The cracking of IdPE and PP yielded lower percentage of heavier fractions $\left(\mathrm{C}_{11^{-}}\right.$ $\mathrm{C}_{16}$ ) compared to hdPE. There is a partial agreement with the present work on the percentage of $\mathrm{C}_{5}-\mathrm{C}_{6}$ fraction except for hdPE using normal mixing which showed a high percentage of $\mathrm{C}_{6}$. On the percentage of heavier fractions $\left(\mathrm{C}_{11}-\mathrm{C}_{16}\right)$, hdPE resulted lower than IdPE and PP but still has a maximum at $\mathrm{C}_{19}-\mathrm{C}_{20}$. These differences are due to the higher reaction temperature used by the latter study as well as the mixing method used. Kim et al. [56] in their work on catalytic copyrolysis of cellulose and thermoplastics over HZSM-5 and HY catalysts study the catalytic pyrolysis of IIdPE and PP. HY has produced large amounts of monocyclic aromatic hydrocarbons, which have a larger carbon number than $\mathrm{C}_{9}$, and polycyclic aromatic hydrocarbons (PAHs) because of its larger pore size and cavities. Similar behavior is shown in figure 8 with a noticeable percentage of $\mathrm{C}_{8}-\mathrm{C}_{16}$ for IIdPE, PP and other polyethylene, which can be linked to these monocyclic and polycyclic hydrocarbons. In a polymer catalytic degradation, at $673 \mathrm{~K}$, the condensed product is mainly composed of olefins and paraffins with increased amounts of aromatic compounds. As the 
temperature increased, there was a reduction in naphthenes and paraffins yield in favour of double bond production indicating that, unsaturation, cyclization and aromatization took place to form aromatics [35]. The conversion of olefin into aromatics took place on different acid sites, and therefore, intermediates are desorbed from one acid site and re-adsorbed on other acid site to be transformed into aromatics [57]. The reaction temperature used in this work was good enough to favor aromatization and pre-degradation treatment has facilitated higher temperature transformations by providing intimate contact that significantly lowered the activation energy. Even though pre-degradation treatment cannot supply additional active sites, it allowed the maximum utilization of the available active sites by minimising the coke formation that blocked the active sites. As pre-degradation treatment has increased the availability of free active sites, more aromatization took place and hence the heavy components associated with this predegradation treatment.

\subsubsection{Effect of pre-degradation treatment on the products distribution from catalytic pyrolysis of PP with different catalysts}

Figure 9 shows the product distribution for catalytic pyrolysis of PP with different zeolite catalysts. The effect of zeolite structure in catalytic pyrolysis is clearly shown in figure 9 with the product distribution been effected variably across all the catalysts. The product distribution with HY zeolite is predominantly lighter carbon atoms $\left(\mathrm{C}_{5}-\mathrm{C}_{10}\right)$, as well as heavier carbon atoms $\left(\mathrm{C}_{11}-\mathrm{C}_{18}\right)$. Based on the hydrocarbon fraction groups, all the pre-degradation treatments have similar percentage of $\mathrm{C}_{5}-\mathrm{C}_{9}$ and $\mathrm{C}_{14}-\mathrm{C}_{20}$. The main difference is that normal mixing has higher percentage of $-\mathrm{C}_{5}$ while pre-degradation treatment contained higher percentage of $\mathrm{C}_{9}-\mathrm{C}_{14}$. The product distribution with USY zeolite is similar to HY zeolite but the former contained heavier carbon atoms up to $\mathrm{C}_{19}-\mathrm{C}_{20}$ and the difference between the pre-degradation treatments are wider. Using normal mixing, USY 
has a peak at $\mathrm{C}_{5}-\mathrm{C}_{6}, \mathrm{C}_{6}-\mathrm{C}_{7}$ and $\mathrm{C}_{7}-\mathrm{C}_{8}$ while the peak shifted to the pre-degradation treatment at $\mathrm{C}_{9}-\mathrm{C}_{10}, \mathrm{C}_{10}-\mathrm{C}_{11}$ and $\mathrm{C}_{11}-\mathrm{C}_{12}$ respectively.
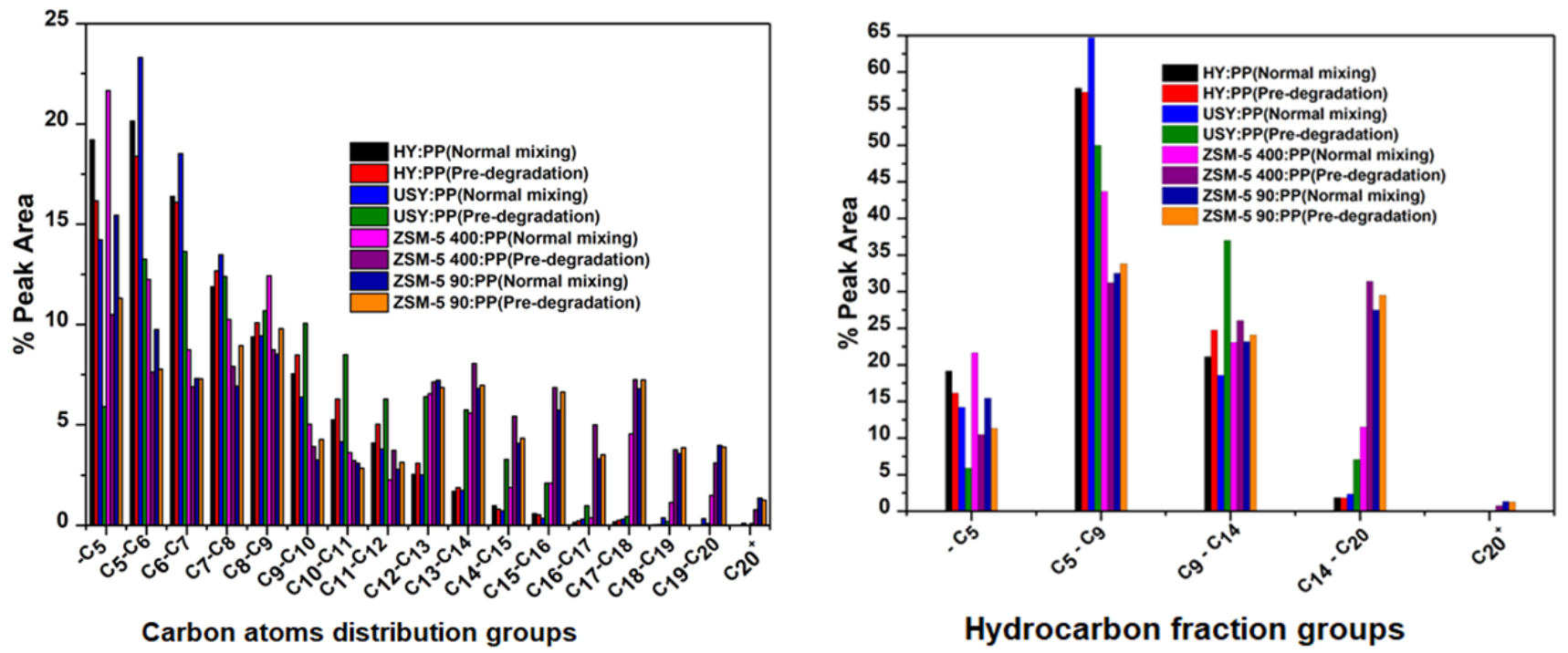

Hydrocarbon fraction groups

Figure 9• Products distribution from catalytic pyrolysis of PP with different catalyst using normal mixing and pre-degradation treatment ( $\mathrm{N}_{2}$ flow rate $=10 \mathrm{~mL} / \mathrm{min}$; polymer, $2 \mathrm{~g}$ : catalyst, $0.5 \mathrm{~g}$; reaction temperature $=723 \mathrm{~K}$ ) based on the carbon atom groups and hydrocarbon fraction groups

Based on the hydrocarbon fraction groups, USY with normal mixing has the maximum percentage of lighter fractions with a peak at $\mathrm{C}_{5}-\mathrm{C}_{9}$. Pre-degradation treatment has more of the middle and heavy fractions with a peak at $\mathrm{C}_{9}-\mathrm{C}_{14}$. The product distribution with ZSM-5 catalysts is wide across all carbon numbers, as well as hydrocarbon fraction groups. For ZSM-5 400 using normal mixing, there is a peak at $-\mathrm{C}_{5}$ and $\mathrm{C}_{8}-\mathrm{C}_{9}$. Pre-degradation treatment has the highest percentage from $\mathrm{C}_{11}$ $\mathrm{C}_{12}$ up to $-\mathrm{C}_{20}{ }^{+}$with a peak at $\mathrm{C}_{13}-\mathrm{C}_{14}---\mathrm{C}_{18}-\mathrm{C}_{19}$. Based on the hydrocarbon fraction groups, the differences between pre-degradation treatments and normal mixing are clear. Normal mixing produced more $\left(-\mathrm{C}_{5}\right)$ and $\mathrm{C}_{5}-\mathrm{C}_{9}$ while pre-degradation treatment more $\mathrm{C}_{9}-\mathrm{C}_{14}$ and $\mathrm{C}_{14}-\mathrm{C}_{20}$. ZSM590 is more acidic than ZSM-5 400 and the product distribution pattern is similar to ZSM-5 400 with wide distribution of carbon atoms $\left(\mathrm{C}_{5}-\mathrm{C}_{20}\right)$ due to their similar properties. ZSM-5 90 showed 
maximum percentage with the heavier carbon atoms $\left(\mathrm{C}_{13}-\mathrm{C}_{20}{ }^{+}\right)$and the differences between the pre-degradation treatments are closer. Based on the hydrocarbon fraction groups, normal mixing is better with the lighter fraction $-C_{5}$ while pre-degradation treatment was better in the subsequent fractions i.e. $C_{5}-C_{9}, C_{9}-C_{14}$ and $C_{14}-C_{20}$.

Kassargy et al. [46] studied the catalytic pyrolysis of polypropylene over USY zeolite with product distribution that has a chain length between $\mathrm{C}_{5}-\mathrm{C}_{15}$ and contained products rich in $\mathrm{C}_{5}-$ $\mathrm{C}_{11}$. As reported by Gulab et al. [52] and Valanciene et al. [58] catalytic thermolysis process at shorter reaction times resulted in more heavy components which decomposed further at longer reaction time. This explained the variations with the results presented in figure 9, as well as possible polymerisation at higher temperature that would be intense with pre-degradation treatment. Miskolczi et al. [55] observed maximum percentage of hydrocarbons at $\mathrm{C}_{9}$ and $\mathrm{C}_{14}$. The maximum at $\mathrm{C}_{9}$ belongs to the propylene trimer, especially from polypropylene content of the raw material. The results obtained from the present study contained the same peak at $\mathrm{C}_{8}-\mathrm{C}_{9}$ and $\mathrm{C}_{13}-\mathrm{C}_{14}$ but these are lower than the maximum percentage at $\mathrm{C}_{5}$, which is in agreement with most literature results. The high concentration of $\mathrm{C}_{8}$ hydrocarbons has been associated with the dimerisation of $\mathrm{C}_{4}$ olefins [59] and the selectivity toward $\mathrm{C}_{10}-\mathrm{C}_{16}$ was obtained because the degradation reactions over HZSM-5 zeolites mainly occur by end chain scission [60]. Palza et al. [61] conducted catalytic pyrolysis of PP with HZSM-5 of different Si/Al ratios and found that the conversion of olefins into aromatics needs catalysts with a large amount of acid sites while high $\mathrm{Si} / \mathrm{Al}$ ratio zeolites are suitable to produce gasoline range product. The product distribution with the two types of HZSM-5 zeolites used in this study have shown similar distribution characteristics. The product distribution with ZSM-5 $400(\mathrm{Si} / \mathrm{Al}$ ratio $=200)$ contained product with maximum amount of $\mathrm{C}_{5}-\mathrm{C}_{9}$ while ZSM-5 $90(\mathrm{Si} / \mathrm{Al}$ ratio $=45)$ has a maximum percentage of heavy components $\mathrm{C}_{14}-\mathrm{C}_{20}$. An interested result here is the comparison of the acidity effect between the two ZSM-5 catalysts. Regardless of it is higher Si/Al ratio, using pre-degradation 
treatment, ZSM-5 400 has produced similar higher amount of $\mathrm{C}_{14}-\mathrm{C}_{20}$. This simply tells that in the presence of fewer acid sites, pre-gradation treatment was able to accomplished important transformation that normally took place on strong acid sites.

Catalytic cracking reactions over HY zeolite are more efficient than ZSM-5 due to the larger surface area and pore size of HY zeolite [45] but ZSM-5 produced larger amounts of light hydrocarbons and aromatics because it has larger amounts of strong Brønsted acid sites [62]. Apart from the Si/Al ratio, the structure of catalysts and their pore size fundamentally determine the cracking properties of the catalyst. As the acidity of catalysts mainly determines the cracking behaviour of $\mathrm{C}-\mathrm{C}$ bonds and the probability of $\beta$-scission, the amorphous part of catalysts fosters the isomerisation and aromatisation reactions [55]. One of the major differences between the $\mathrm{Y}$ zeolite, USY and ZSM-5 is the catalyst pore size and structure [63]. Y zeolite and USY have large cages with large openings $(7.4 \AA)$ and are able to allow large molecules to diffuse relatively easily into the internal acid sites for further cracking and product selectivity [64]. The ZSM-5 zeolite has a three-dimensional system of intersecting channels with a medium pore size opening $(5.5 \AA)$ and permits selectively smaller molecules for conversion into mainly light hydrocarbon and aromatics [65].

\subsubsection{Effect of catalyst content on the products distribution from catalytic pyrolysis of PP with HY zeolite}

Figure 10 shows the products distribution for catalytic pyrolysis of PP with HY zeolite using different amounts of catalyst emphasising the effect of the catalyst content was outlined as the amount of each carbon atom number hydrocarbon fraction changes with increasing catalyst content. 


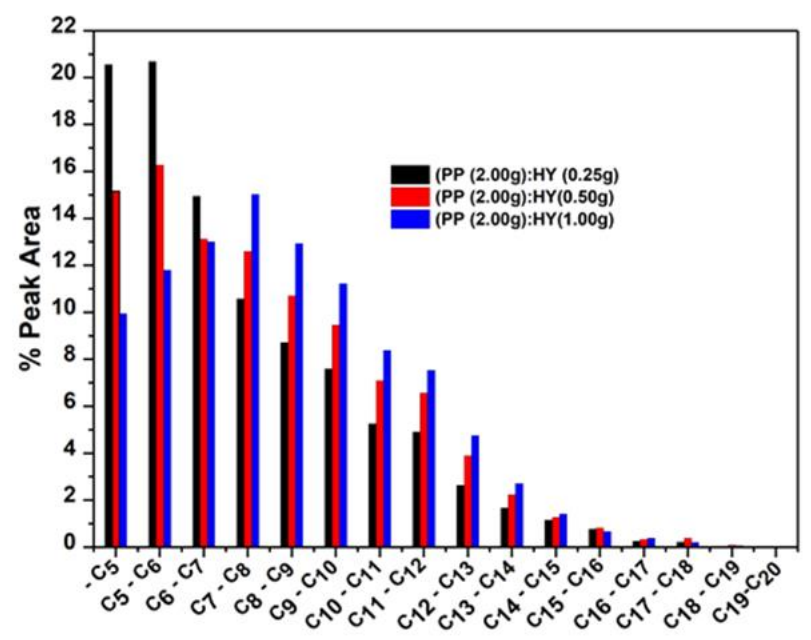

Carbon atoms distribution groups

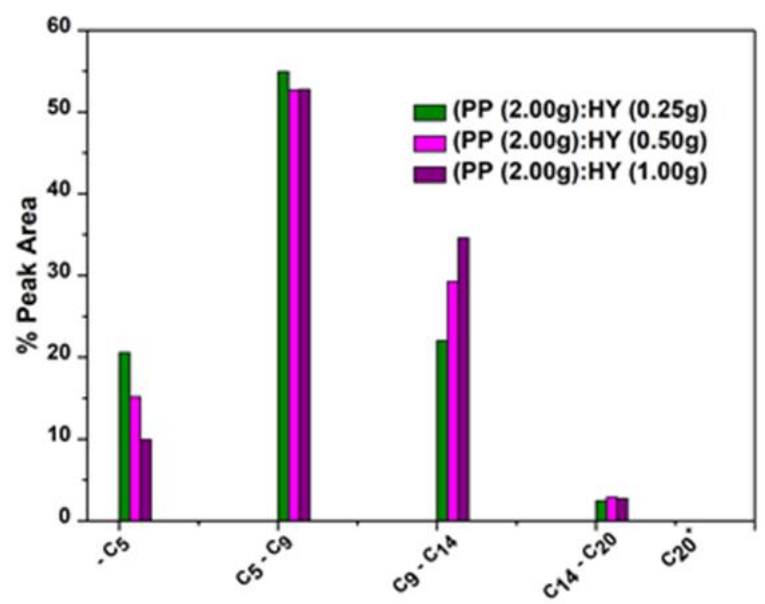

Hydrocarbon fraction groups

Figure 10• Products distribution from catalytic pyrolysis of PP with HY zeolite

$\left(\mathrm{N}_{2}\right.$ flow rate $=10 \mathrm{~mL} / \mathrm{min}$; reaction temperature $\left.=723 \mathrm{~K}\right)$ based on the carbon atom groups and hydrocarbon fraction groups

As presented in figure 10, the amount of the lighter carbon atoms decreased with increasing catalyst content but this pattern reverses at $\mathrm{C}_{7}-\mathrm{C}_{8}$ and increased with increasing catalyst content. The pattern is the same with hydrocarbon fraction groups where the lower amount of catalyst favoured the lighter fraction $\left(-C_{5}\right)$ and higher amount of catalyst favoured the heavier fraction $\left(\mathrm{C}_{9}-\right.$ $\mathrm{C}_{14}$ ). Similar studies have reported the effect of catalyst content on the product distribution. The results of these studies showed a reversed pattern in the product distribution as shown in figure 10. Abbas-Abadi et al. [35] studied the effect of increasing the catalyst/PP ratio from 0.1 to 0.6 during catalytic cracking of $\mathrm{PP}$ at $723 \mathrm{~K}$. As the catalyst/PP ratio increases, the percentage $\mathrm{C}_{5}-\mathrm{C}_{7}$ increases while the amount of $\mathrm{C}_{8}-\mathrm{C}_{14}$ decreases and the sum of $\left(\mathrm{C}_{5}-\mathrm{C}_{9}\right)$ did not change significantly. Gulan et al. [52] conducted catalytic pyrolysis of hdPE with USY using polymer to catalyst ratios of $2: 1,4: 1$ and $8: 1$ for different experiments. The product distribution showed that, as the catalyst/polymer ratio increases, the percentage $C_{5}-C_{7}$ increases while amount of $C_{9}-C_{12}$ decreases. The results presented in figure 10 showed more clear pattern and difference than the 
literature results. The variations in the product distribution is because of the pre-degradation treatment used in this work, as well as the disparities in the reaction time. Pre-degradation treatment permits catalytic degradation to finish within a short period [33] while the literature results reported took place over a long reaction time. As discussed before, the differences in the product distribution due to increased temperature and/ catalyst content can be insignificant at longer reaction times. As shown in the previous results, pre-degradation treatment maximised the medium and heavy fractions, which is also in line with the results presented in figure 10.

\subsubsection{Effect of different method, pre-degradation treatment and co- pressing, on the product distribution from catalytic pyrolysis of mdPE with HY zeolite}

Figure 11 compares more pre-degradation treatment methods including co-pressing of powder powder mixture of polymer and catalyst. The results include the effect of flow rate and predegradation treatment temperature. The sample polymer has a lower melting and can easily turn into liquid at lower pre-degradation treatment temperature.
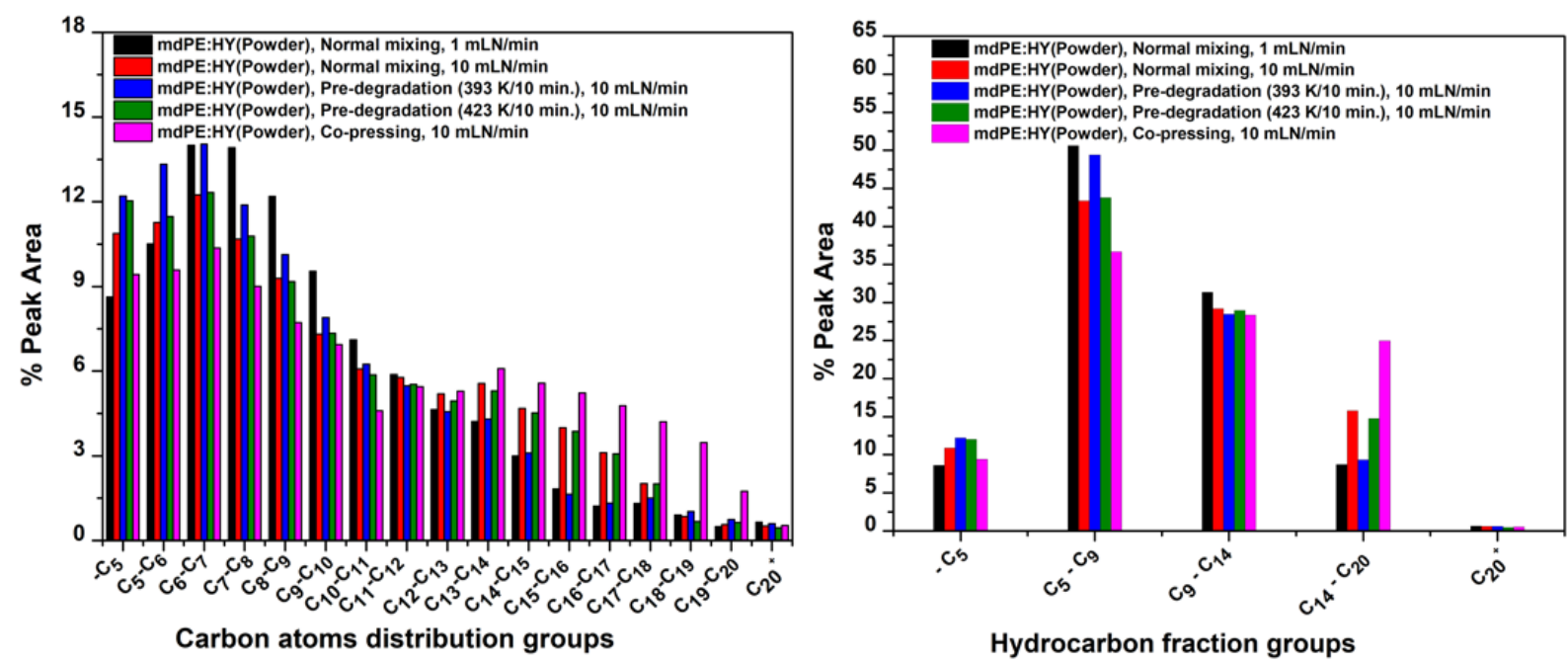

Hydrocarbon fraction groups

Figure 11• Products distribution from catalytic pyrolysis of mdPE with HY zeolite using different 
pre-degradation treatment method and $\mathrm{N}_{2}$ flow rate (polymer, $2 \mathrm{~g}$ : catalyst, $0.5 \mathrm{~g}$; reaction temperature $=723 \mathrm{~K}$ ) based on the carbon atom groups and hydrocarbon fraction groups

As shown in figure 11, increasing the flow rate from 1 to $10 \mathrm{~mL} / \mathrm{min}$ resulted to changes in the product distribution. At lower flow rate there are peaks at $C_{6}-C_{7}, C_{7}-C_{8}--$-even $C_{11}-C_{12}$ while the higher flow rate shows higher percentage of $-C_{5}, C_{5}-C_{6}$ but also heavier components $C_{12}-C_{13}$ - $-\mathrm{C}_{17}-\mathrm{C}_{18}$. Based on the hydrocarbon fraction groups, the lower flow rate shows peaks at $\mathrm{C}_{5}-\mathrm{C}_{9}$ and $\mathrm{C}_{9}-\mathrm{C}_{14}$ while higher flow rate has higher amount of volatiles $\left(-\mathrm{C}_{5}\right)$ and $\mathrm{C}_{14}-\mathrm{C}_{20}$ respectively. The last four results in figure 11 compared different pre-degradation treatment methods at constant flow rate. Among the four pre-degradation treatment methods used, pre-degradation treatment at $393 \mathrm{~K}$ for $10 \mathrm{~min}$. showed the maximum amount of $-\mathrm{C}_{5}$ and $\mathrm{C}_{5}-\mathrm{C}_{11}$ followed by predegradation treatment at $423 \mathrm{~K}$, then normal mixing while co-pressing has the highest percentage of $\mathrm{C}_{13}-\mathrm{C}_{20}$. Based on the hydrocarbon fraction groups, pre-degradation treatment resulted to higher amounts of $-\mathrm{C}_{5}$ followed by normal mixing while co-pressing method contained the lowest percentage. The percentage of the middle fraction $\left(\mathrm{C}_{9}-\mathrm{C}_{14}\right)$ was similar across the predegradation treatment methods. For the light fraction $\left(\mathrm{C}_{5}-\mathrm{C}_{9}\right)$, pre-degradation treatment at low temperature has the highest percentage with pre-degradation treatment at higher temperature and normal mixing having the same percentage while co-pressing method has the lowest percentage. The distribution of heavy fraction $\mathrm{C}_{14}-\mathrm{C}_{20}$ among the pre-degradation treatment methods is of the order co-pressing $>$ normal mixing $>$ pre-degradation treatment at $423 \mathrm{~K}>$ predegradation treatment at $393 \mathrm{~K}$. Gulab et al. [55] studied the effect of $\mathrm{N}_{2}$ flow rate during catalytic degradation of hdPE with USY catalyst. They conducted different experiments with 5, 10 and 50 $\mathrm{mL}_{\mathrm{N}} / \mathrm{min}$ respectively. The results showed that increasing the flow rate to $50 \mathrm{~mL} / \mathrm{min}$ lowers the percentage of lighter fractions while there is no significant difference between 5 and $10 \mathrm{~mL} / \mathrm{min}$. This is in line with the overall pattern obtained from this study where $1 \mathrm{~mL} / \mathrm{min}$ has the maximum percentage of lighter fractions and $10 \mathrm{~mL} / \mathrm{min}$ contained maximum heavier fractions due to the 
shorter residence time of the volatiles in the reactor. Schirmer et al. [66] carried out catalytic pyrolysis of polyethylene with HY catalyst in a cycled-spheres-reactor. The product spectrum from catalytic degradation shifted drastically to lower carbon numbers with a peak at $\mathrm{C}_{7}$. The product distribution curves of catalytic degradation clearly show maxima with $\mathrm{C}_{16}$ as the heaviest carbon atom reported. Valanciene et al. [58] also reported similar product distribution $\left(\mathrm{C}_{5}-\mathrm{C}_{20}\right)$ for catalytic thermolysis of polyethylene with $\mathrm{C}_{7}-\mathrm{C}_{9}$ as predominant compounds in the liquid products. Bagri and Williams [67] related Y-zeolite with higher concentrations of single ring aromatic and polycyclic aromatic hydrocarbons compared to the ZSM-5 zeolite. The higher pore size of $\mathrm{Y}$ zeolite allows larger molecules to enter the catalyst and undergo catalytic aromatization reactions, thereby increasing the amount of single ring and aromatic compounds. The Y-zeolite in this work has higher surface acidity that can drastically enhance the yields of the single ring and polycyclic aromatic hydrocarbons.

Based on the performance of the pre-degradation treatment methods, normal mixing produced the maximum amount of lighter fractions and therefore pre-degradation treatment can be used to enhance the gasoline fraction while the diesel fraction can be maximised using copressing method. 


\subsubsection{Products distribution from thermal pyrolysis of IldPE and PP}

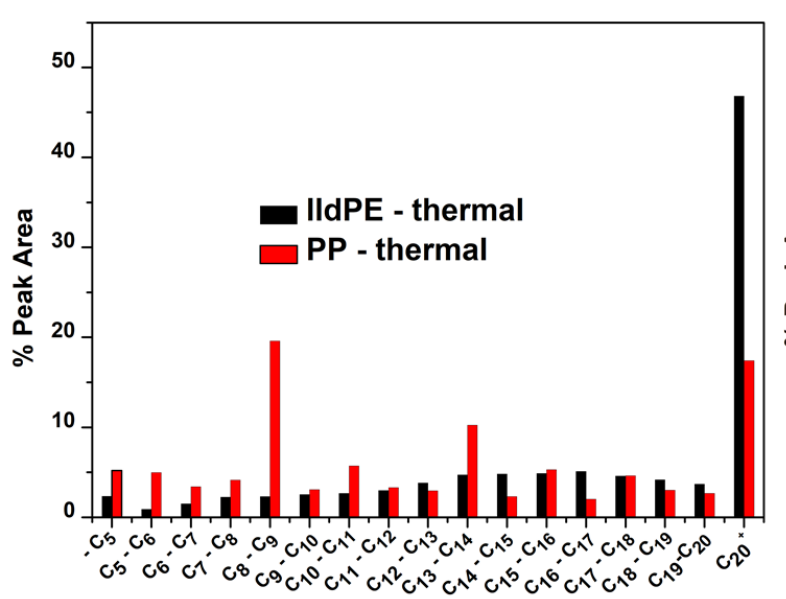

Carbon atoms distribution groups

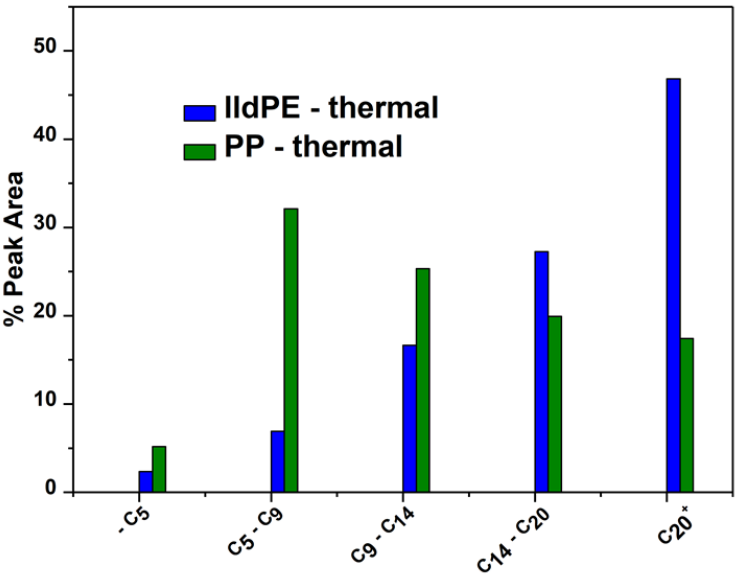

Hydrocarbon fraction groups

Figure 12• Products distribution from thermal pyrolysis of IIdPE and PP

$\left(\mathrm{N}_{2}\right.$ flow rate $=100 \mathrm{~mL}_{\mathrm{N}} / \mathrm{min}$; reaction temperature $\left.=723 \mathrm{~K}\right)$ based on the carbon atom groups and hydrocarbon fraction groups

Figure 12 shows the products distribution from thermal cracking of IldPE and PP. The product distribution varies accordingly due to the differences in their structure. The non-catalytic thermal cracking of PP produces lighter carbon atoms with a peak in the following order $\mathrm{C}_{8}-\mathrm{C}_{9}>-\mathrm{C}_{20}{ }^{+}>$ $\mathrm{C}_{13}-\mathrm{C}_{14}>\mathrm{C}_{10}-\mathrm{C}_{11}>\mathrm{C}_{15}-\mathrm{C}_{16}>-\mathrm{C}_{5}>\mathrm{C}_{5}-\mathrm{C}_{6}>\mathrm{C}_{17}-\mathrm{C}_{18}>\mathrm{C}_{7}-\mathrm{C}_{8}$ while the thermal cracking of IIdPE produces mainly waxes in the carbon atoms range of $\mathrm{C}_{20}{ }^{+}$. Based on the hydrocarbon fraction groups, the product distribution from thermal cracking of PP were formed in the following order $\mathrm{C}_{5}-\mathrm{C}_{9}>\mathrm{C}_{9}-\mathrm{C}_{14}>\mathrm{C}_{14}-\mathrm{C}_{20}>\mathrm{C}_{20}{ }^{+}>-\mathrm{C}_{5}$ while IldPE had the following order $\mathrm{C}_{20}{ }^{+}>\mathrm{C}_{14}-\mathrm{C}_{20}>\mathrm{C}_{9}-\mathrm{C}_{14}$ $>\mathrm{C}_{5}-\mathrm{C}_{9}>-\mathrm{C}_{5}$. A wide spectrum of hydrocarbon fragments formed from the thermal degradation of IIdPE and PP shows that the random polymer chain scission is the ruling mechanism in their thermal degradation. Considering the products obtained from PP in this work, hydrogen intramolecular transfer and $\beta$-scission of end or middle chain radicals are the dominant mechanisms. For IdPE, hydrogen intermolecular transfer and $\beta$-scission followed by hydrogen intramolecular transfer contributed to the formation of normal alkanes and 1-alkenes with same 
carbon number as described by the following related studies. Yan et al. [68] carried out thermal cracking of IdPE in a semi-batch reactor. The products were characterized by a series of double peaks, corresponding to n-alkanes and 1-alkenes (1-olefins), respectively, having the same carbon number. For PP a large number of compounds with carbon double bonds $(\mathrm{C}=\mathrm{C})$ were obtained with higher yields of branched hydrocarbons, because of the presence of the $\mathrm{CH}_{3}$ side group in the PP structure. The carbon distribution from thermal cracking of IdPE ranges from $\mathrm{C}_{6}$ to $\mathrm{C}_{30}$ dominated by diesel $\left(\mathrm{C}_{13}-\mathrm{C}_{22}\right)$ fraction while PP resulted in mostly alkenes (2,4-dimethyl-1heptene) which accounts for 18.26 wt \%. Kim et al. [56] also reported that the thermal pyrolysis of PP predominantly produced $\mathrm{C}_{5}-\mathrm{C}_{11}$ while IldPE largely produced compounds greater than $\mathrm{C}_{11}$ carbon atom. These studies confirmed the results obtained from this study. The higher volatile compounds obtained from PP in contrast to IldPE is due to the difference in their structure. PP is a polymer whose chains present a greater cross-sectional area than IIdPE, due to the presence of the methyl group substituent on alternate carbon atoms of the chain [46]. The methyl groups in PP structure has increased the number of tertiary carbon atoms, which considerably lower it is thermal resistance against degradation and promotes the cleavage of C-C bonds [69].

\subsection{Coked catalyst characterization}

TGA is widely used to quantify the amount of coke on a surface, and to characterise the composition of carbonaceous materials in terms of their fixed carbon content, moisture, ash content and volatile components [31] [70]. The determination of coke amount involves different heat treatments to remove water adsorbed in the course of obtaining the sample from the laboratory reactor, as well as adsorbed reactants and volatile products. Paweewan et al. [71] measured the amount of coke by considering the weight loss by burning coke at high temperature (973 K), ignoring the removal of any volatile light coke components. In another study, Brillis and Manos [72] determined the amount of the coke by removing water at a low temperature of $473 \mathrm{~K}$, 
which then increases to $1123 \mathrm{~K}$ at a rate of $10 \mathrm{~K} / \mathrm{min}$ in air atmosphere. The amount of the coke corresponds to the total weight loss from the initial heat treatment at $473 \mathrm{~K}$ to the final temperature at $1123 \mathrm{~K}$ [72].

Coke precursors are chemically active and they are intermediates in the reaction network. During the period of increasing temperature, the volatile light coke molecules as well as heavy adsorbed coke molecules can undergo cracking to yield smaller molecules, which are latter desorbed or transformed via dehydrogenation into more condensed coke species [70]. Coke components can be classified by considering different chemical character of the coke precursors, revealing more quantitative information of coke formation not taken into consideration in previous works. Chen and Manos [70], and Wang and Manos [73] classified coke into coke precursors and hard coke. Coke precursors were removed from the catalyst sample simply through volatilisation in inert nitrogen, whereas hard coke remains on the catalyst even at high temperature (873 K) and was removed by burning. Based on the latest methodology, this study used a final temperature of $1173 \mathrm{~K}$. In inert atmosphere, coke precursors can be removed from coked catalyst up to a temperature of $1173 \mathrm{~K}$, beyond this temperature the process was static in inert and therefore, nonoxidative atmosphere was used to remove the hard coke usually trapped in the pores of the catalyst.

\subsubsection{Coke classification from catalytic pyrolysis of different polymer and catalysts}

Table 2 shows the results of percentage soft and hard coke as well as coke concentration from different polymers and catalysts.

Table 2: Coked catalysts classification from catalytic pyrolysis of different polymers and catalysts (polymer, 2g: catalyst, 1g; reaction temperature $=723 \mathrm{~K}, \mathrm{~N}_{2}$ flow rate $=50 \mathrm{~mL}_{N} / \mathrm{min}$ )

\section{Coke Classification}




\begin{tabular}{llll} 
Experiment type & \% Soft Coke & \% Hard Coke & Coke Concentration \\
\hline IIdPE:USY & 64.00 & 36.00 & 0.29 \\
IdPE:USY & 33.00 & 67.00 & 0.21 \\
PP:USY & 12.80 & 87.20 & 0.29 \\
IIdPE:ZSM-5 & 72.30 & 27.70 & 0.02 \\
IIdPE:HY (2.0g:1.0g) & 59.14 & 40.86 & 0.29 \\
IIdPE:HY (2.0g:0.5g) & 56.72 & 43.28 & 0.36 \\
\hline
\end{tabular}

The volatility of the coke components depend on the percentage soft coke of the coked catalyst. Higher percentage of hard coke are associated with heavy polymeric aromatic compounds trapped within the pores of the catalyst. Based on different polymers with USY catalyst, the volatility of the coke components is of the following order IIdPE $>$ IdPE $>$ PP. The concentration of coke is the same for IIdPE and PP while IdPE has the least coke concentration. According to the catalyst type the volatility of coke components is of following order ZSM-5 > USY > HY. The concentration of coke is the same for USY and HY while ZSM-5 showed very low concentration of coke. The volatility of the coke increases while coke concentration decreases with increased in catalyst amount. The differences in the coke composition has to do with the structure of the polymer. Branched polymer (PP and IDPE) molecular structure could improve the formation of coke molecules but also easier the penetration of polymer fragments into to the active sites located in pores leading to the greater extension of the catalytic reactions, and so the greater coke deposition (hard coke) [51]. On the other hand, PP chains present a greater cross-sectional area compared to IdPE, due to the presence of the methyl group substituent. The branched structure of PP allowed the formation of methyl, primary and secondary alkyl radicals promoting aromatization reactions and coke formation [46].

The rate of coke formation depend on the number and strength of active sites, the pore structure, and the temperature [22]. The growth of the coke molecules were hindered in ZSMS-5 
pores due to the shape selectivity properties of its relatively small pore structure and, consequently, smaller coke retention was observed [13] [74]. The presence of supercages (2.5 $\mathrm{nm}$ ) in the $\mathrm{Y}$ and USY frameworks accounted for the higher coke formation.

\subsubsection{The influence of pre-degradation treatment on coke classification}

Table 3: Coked catalysts classification from catalytic pyrolysis of IIdPE with HY catalyst

(Polymer, 2g: catalyst, 1g; reaction temperature $=683 \mathrm{~K}, \mathrm{~N}_{2}$ flow rate $=30 \mathrm{~mL}_{\mathrm{N}} / \mathrm{min}$ )

\begin{tabular}{llll}
\hline \multicolumn{4}{c}{ Coke Classification } \\
\hline Experiment type & \% Soft Coke & \% Hard Coke & Coke Concentration \\
\hline Normal mixing & 30.00 & 70.00 & 0.21 \\
5 min. pre-degradation treatment & 40.00 & 60.00 & 0.21 \\
15 min. pre-degradation treatment & 72.00 & 28.00 & 0.22 \\
\hline
\end{tabular}

As shown in table 3, pre-degradation treatment facilitated the formation of more volatile coke components that are easy to remove in inert atmosphere but the total coke concentration from the same catalyst and polymer remain the same. As shown in table 2 , the percentage of soft coke increases with increased catalyst loading because of the shorter residence time of the volatiles in the rector restricting the secondary reactions leading to the coke formation. For the same reason, the percentage of soft coke increases with increased contact between polymer and catalyst. Normal mixing formed more hard coke while $15 \mathrm{~min}$. pre-degradation treatment produced predominantly soft coke. 


\section{Conclusions}

Pre-treatment processes using physical, mechanical and thermal treatments were used to provide intimate contact between the polymer and catalyst. The main conclusions of this study are as following:

- TGA results showed that pre-degradation treatment lowers the degradation temperature of polymer.

- The effect of pre-degradation treatment in promoting the liquid yield depends on the polymer structure and the catalyst type. Linear polymer like hdPE and to a lesser extent IldPE produced higher liquid yields with pre-degradation treatment compared to branched polymers like IdPE and PP.

- At low pyrolysis temperature, HY zeolite produced higher liquid yield while at higher pyrolysis temperature USY zeolite showed better performance.

- The product distribution of PP with HY zeolite has the highest percentage of lighter fraction and hdPE showed maximum percentage of $\mathrm{C}_{5}-\mathrm{C}_{6}$ but the all polymers showed maximum amount of gasoline range fraction $\mathrm{C}_{5}-\mathrm{C}_{9}$. With all the polymers and catalysts, pre-degradation treatment has maximised the gasoline fraction $C_{5}-C_{12}$ and heavier fraction $C_{13}-C_{20}$.

- Thermal cracking of IIdPE produced predominantly $\mathrm{C}_{20}{ }^{+}$while this of PP contained lighter fractions with maximum percentage of $\mathrm{C}_{8}-\mathrm{C}_{9}$.

- The volatility of the coke components based on the polymer type is of the following order lldPE $>$ IdPE $>$ PP. According to the catalyst type the volatility of coke components is of following order ZSM-5 > USY > HY. The concentration of coke is the same for USY and HY while it was very low for ZSM-5. 


\section{Acknowledgements}

The authors gratefully acknowledge PhD funding (IM) from Petroleum Technology Development

Fund (PTDF), Nigeria. A special thanks to the management of NICE (Nature Inspired Chemical

Engineering) lab facility University College London for the support received during the GC and

TGA analysis.

\section{References}

[1] Marcilla A., Beltran M.I., Gomez-Siurana, Navarro R., Valdes F. (2007) A global kinetic model as a tool to reproduce the deactivation behaviour of the HZSM-5 zeolite in the catalytic cracking of low-density polyethylene. Applied Catalysis A: General 328:124-131

https://doi.org/10.1016/i.apcata.2007.05.038

[2] Pamreishang Kasar, D.K. Sharma, M. Ahmaruzzaman. Thermal and catalytic decomposition of waste plastics and its co-processing with petroleum residue through pyrolysis process. Journal of Cleaner Production 2020, 265, 121639. https://doi.org/10.1016/i.jclepro.2020.121639

[3] Olivera, M., Musso, M., De León, A., Volonterio, E., Amaya, A., Tancredi, N. and Bussi, J., 2020. Catalytic assessment of solid materials for the pyrolytic conversion of low-density polyethylene into fuels. Heliyon, 6(9), p.e05080. doi: 10.1016/j.heliyon.2020.e05080

[4] Bucknall, D., 2020. Plastics as a Materials System in a Circular Economy. Philosophical Transactions of the Royal Society A: Mathematical, Physical and Engineering Sciences.

https://doi.org/10.1098/rsta.2019.0268

[5] Fan ZHANG, Yuting ZHAO, Dandan WANG, Mengqin YAN, Jing ZHANG, Pengyan ZHANG, Tonggui DING, Lei CHEN, Chao CHEN. Current technologies for plastic waste treatment: A review. Journal of Cleaner Production 2020, 124523.

https://doi.org/10.1016/i.jclepro.2020.124523

[6] M Ahmaruzzaman, DK Sharma Non-isothermal kinetic studies on co-processing of vacuum residue, plastics, coal and petrocrop J Anal Appl Pyrolysis, 73 (2005), pp. 263-275

https://doi.org/10.1016/j.jaap.2004.11.035

[7] Parku, G.K., Collard, F.X. and Görgens, J.F., 2020. Pyrolysis of waste polypropylene plastics for energy recovery: Influence of heating rate and vacuum conditions on composition of fuel product. Fuel Processing Technology, 209, p.106522.

https://doi.org/10.1016/i.fuproc.2020.106522

[8] M. Ahmaruzzaman, D. K. Sharma, Coprocessing of petroleum vacuum residue with plastics, coal, and biomass and its synergistic effects, Energy and Fuels 21 (2) (2007) 891-897 https://doi.org/10.1021/ef060102w

[9] M. Ahmaruzzaman \& D. K. Sharma (2013) TG-DTA Studies on the Cracking of Petroleum Vacuum Residue and Its Co-cracking with Plastics, Coal, and Biomass, Energy Sources, Part A: Recovery, Utilization, and Environmental Effects, 35:17, 1670-1679

https://doi.org/10.1080/15567036.2010.523759

[10] Plastics-The Facts, An Analysis of European Plastics Production, Demand and Waste Data, Plastic Europe, EuPC, EuPR and EPRO, 2017.

https://www.plasticseurope.org/en/resources/market-data

[11] M. Kamboj, Degradation of plastics for clean environment, International Journal of Advanced Research in Engineering and Applied Sciences 5 (2016) 1-19. 
http://www.garph.co.uk/IJAREAS/Mar2016/2.pdf

[12] C. Kassargy, S. Awad, G. Burnens, K. Kahine, M. Tazerout, Gasoline and diesel-like fuel production by continuous catalytic pyrolysis of waste polyethylene and polypropylene mixtures over USY zeolite, Fuel 224 (2018) 764-773. https://doi.org/10.1016/i.fuel.2018.03.113

[13] K. Gobin, G. Manos, Polymer degradation to fuels over microporous catalysts as a novel tertiary plastic recycling method, Polymer Degradation and Stability 83 (2004) 267-279

https://doi.org/10.1016/S0141-3910(03)00272-6

[14] G. Manos, A. Garforth, J. Dwyer, Catalytic degradation of high-density polyethylene on an ultrastable-Y zeolite. Nature of initial polymer reactions, pattern of formation of gas and liquid products, and temperature effects, Industrial Engineering and Chemistry Research 39 (2000) 1203-1208. https://pubs.acs.org/doi/abs/10.1021/ie990513i

[15] S. L. Wong, N. Ngadi, T. A. T. Abdullah, I. M. Inuwa, Current state and future prospects of plastic waste as source of fuel: A review, Renewable and Sustainable Energy Reviews 50 (2015) 1167-1180. https://doi.org/10.1016/i.rser.2015.04.063

[16] Ahamed, R., Hossain, S., Haque, M. and A. lqbal, S., 2020. Recovery of hydrocarbon fuel from a mixture of municipal waste plastics using a catalyst. International Journal of Sustainable Engineering, pp.1-12. https://doi.org/10.1080/19397038.2020.1773565

[17] Quesada, L., Calero de Hoces, M., Martín-Lara, M.A., Luzón, G. and Blázquez, G., 2020. Performance of Different Catalysts for the In Situ Cracking of the Oil-Waxes Obtained by the Pyrolysis of Polyethylene Film Waste. Sustainability, 12(13), p.5482.

https://doi.org/10.3390/su12135482

[18] G. Manos, I. Y. Yusof, N. H. Gangas, N. Papayannakos, Tertiary recycling of polyethylene to hydrocarbon fuel by catalytic cracking over aluminum pillared clays, Energy and Fuels 16 (2002) 485-489. https://pubs.acs.org/doi/abs/10.1021/ef0102364

[19] G. Manos, I. Y. Yusof, N. Papayannakos, N. H. Gangas, Catalytic cracking of polyethylene over clay catalysts. Comparison with an ultrastable $\mathrm{Y}$ zeolite, Industrial and engineering chemistry research 40 (2001) 2220-2225. https://pubs.acs.org/doi/abs/10.1021/ie0010480

[ 20] Y. H. Lin, M. H. Yang, Tertiary recycling of commingled polymer waste over commercial FCC equilibrium catalysts for producing hydrocarbons, Polymer Degradation and Stability 94 (2009) 25-33. https://doi.org/10.1016/j.polymdegradstab.2008.10.018

[21] N. Miskolczi, L. Bartha, G. Deák, Thermal degradation of polyethylene and polystyrene from the packaging industry over different catalysts into fuel-like feed stocks, Polymer degradation and stability 91 (2006) 517-526. https://doi.org/10.1016/j.polymdegradstab.2005.01.056

[22] G. Manos, A. Garforth, J. Dwyer, Catalytic degradation of high-density polyethylene over different zeolitic structures, Industrial and engineering chemistry research 39 (2000) 1198-1202. https://pubs.acs.org/doi/abs/10.1021/ie990512q

[23] Mark, L.O., Cendejas, M.C. and Hermans, I., 2020. The Use of Heterogeneous Catalysis in the Chemical Valorization of Plastic Waste. ChemSusChem.

https://doi.org/10.1002/cssc.202001905

[24] N. S. Akpanudoh, K. Gobin, G. Manos, Catalytic degradation of plastic waste to liquid fuel over commercial cracking catalysts: effect of polymer to catalyst ratio/acidity content, Journal of Molecular Catalysis A: Chemical 235 (2005) 67-73.

https://doi.org/10.1016/j.molcata.2005.03.009

[25] H. Ohkita, R. Nishiyama, Y. Tochihara, T. Mizushima, N. Kakuta, Y. Morioka, A. Ueno, Y. Namiki, S. Tanifuji, Acid properties of silica-alumina catalysts and catalytic degradation of polyethylene, Industrial and Engineering Chemistry Research 32 (1993) 3112-3116.

https://pubs.acs.org/doi/abs/10.1021/ie00024a021

[26] R. Van Grieken, D. P. Serrano, J. Aguado, R. Garcia, C. Rojo, Thermal and catalytic cracking of polyethylene under mild conditions, Journal of Analytical and Applied Pyrolysis 58 (2001) 127142. https://doi.org/10.1016/S0165-2370(00)00145-5 
[27] J. Aguado, J. L. Sotelo, D. P. Serrano, J. A. Calles, J. M. Escola, Catalytic Conversion of Polyolefins into Liquid Fuels over MCM-41: Comparison with ZSM-5 and Amorphous $\mathrm{SiO}_{2}-\mathrm{Al}_{2} \mathrm{O}_{3}$, Energy and fuels 11 (1997) 1225-1231. https://pubs.acs.org/doi/10.1021/ef970055v

[28] J. K. Jeon, Y. K. Park, Pyrolysis of an LDPE-LLDPE-EVA copolymer mixture over various mesoporous catalysts, Korean Journal of Chemical Engineering 29 (2012) 196-200.

https://doi.org/10.1007/s11814-011-0190-6

[29] S. J. Choi, Y. K. Park, K. E. Jeong, T. W. Kim, H. J. Chae, S. H. Park, J. K. Jeon, S. S. Kim, Catalytic degradation of polyethylene over SBA-16, Korean Journal of Chemical Engineering 27 (2010) 1446-1451. https://doi.org/10.1007/s11814-010-0281-9

[30] Cumming, K. A.; Wojciechowski, B. W. (1996) Hydrogen Transfer, Coke Formation, and Catalyst Decay and Their Role in the Chain Mechanism of Catalytic Cracking. Catal. Rev.-Sci. Eng. 38:101 https://doi.org/10.1080/01614949608006455

[31] Chen S., Manos G. (2004) In situ thermogravimetric study of coke formation during catalytic cracking of normal hexane and 1-hexene over ultrastable Y zeolite, Journal of Catalysis, 226:343350 https://doi.org/10.1016/j.jcat.2004.06.004

[32] P.D. Hopkins, A.T. Miller (1996) Acidity and cracking activity changes during coke deactivation of ultrastable y-zeolite", Applied catalysis. A, General, 136(1) :29-48

https://doi.org/10.1016/0926-860X(95)00246-4

[33] Muhammad I, Makwashi N, Manos G, Catalytic Degradation of Linear Low-density Polyethylene over HY zeolite via Pre-degradation treatment Method, Journal of Analytical and Applied Pyrolysis (2018) https://doi.org/10.1016/j.jaap.2018.11.025

[34] A. Marcilla, M. del R. Hernández, Á. N. García, Study of the polymer-catalyst contact effectivity and the heating rate influence on the HDPE pyrolysis, Journal of Analytical and Applied Pyrolysis79 (2007) 424-432 https://doi.org/10.1016/i.jaap.2006.10.017

[35] M.S. Abbas-Abadi, M.N. Haghighi, H. Yeganeh, The effect of temperature, catalyst, different carrier gases and stirrer on the produced transportation hydrocarbons of LLDPE degradation in a stirred reactor, Journal of Analytical and Applied Pyrolysis 95 (2012) 198-204. https://doi.org/10.1016/i.jaap.2012.02.007

[36] V. P. Caldeira, A. G. Santos, D. S., Oliveira, R. B. Lima, L. D. Souza, S. B. Pergher, Polyethylene catalytic cracking by thermogravimetric analysis, Effects of zeolitic properties and homogenization process, Journal of Thermal Analysis and Calorimetry130(2017) 1939-1951 https://doi.org/10.1007/s10973-017-6551-6

[37] A. Marcilla, A. Gómez-Siurana, J. G. Quesada, D. Berenguer, Characterization of high-impact polystyrene by catalytic pyrolysis over Al-MCM-41: Study of the influence of the contact between polymer and catalyst, Polymer Degradation and Stability 92 (2007) 1867-1872 https://doi.org/10.1016/i.polymdegradstab.2007.06.016

[38] Bagri, R. and Williams, P.T., 2002. Catalytic pyrolysis of polyethylene. Journal of Analytical and Applied Pyrolysis, 63(1), pp.29-41 https://doi.org/10.1016/S0165-2370(01)00139-5

[39] P.T. Williams, Waste Treatment and Disposal, John Wiley and Sons, Chichester, UK, 1998. http://worldcat.org/isbn/0471981494

[40] W Kaminsky Thermal recycling of polymers J. Anal. Appl. Pyrolysis, 8 (1985), pp. 439-446 https://doi.org/10.1016/0165-2370(85)80042-5

[41] Y.H Lin, P.N Sharratt, A.A Garforth, J Dwyer Catalytic conversion of polyolefins to chemicals and fuels over various cracking catalysts Energy Fuels, 12 (1998), pp. 767-774

https://doi.org/10.1021/ef970233k 
[42] P.B. Weisz Molecular shape selective catalysis Pure Appl. Chem., 52 (1980), p. 2091 https://doi.org/10.1351/pac198052092091

[43] B. Smit, T.L.M. Maesen Molecular simulations of zeolites: Adsorption, diffusion, and shape selectivity Chem. Rev., 108 (2008), p. 4125 https://doi.org/10.1021/cr8002642

[44] Jae, J., Tompsett, G.A., Foster, A.J., Hammond, K.D., Auerbach, S.M., Lobo, R.F. and Huber, G.W., 2011. Investigation into the shape selectivity of zeolite catalysts for biomass conversion. Journal of Catalysis, 279(2), pp.257-268

https://doi.org/10.1016/i.jcat.2011.01.019

[45] Marcilla, A.; Beltrán, M. I.; Hernández, F.; Navarro, R. HZSM5 and HUSY deactivation during the catalytic pyrolysis of polyethylene Appl. Catal., A 2004, 278, 37- 43

DOI: 10.1016/i.apcata.2004.09.023

[46] Kassargy, C., Awad, S., Burnens, G., Kahine, K. and Tazerout, M., 2017. Experimental study of catalytic pyrolysis of polyethylene and polypropylene over USY zeolite and separation to gasoline and diesel-like fuels. Journal of Analytical and Applied Pyrolysis, 127, pp.31-37 https://doi.org/10.1016/i.jaap.2017.09.005

[47] G. Lopez, M. Artetxe, M. Amutio, J. Bilbao, M. Olazar, Thermochemical routes for the valorization of waste polyolefinic plastics to produce fuels and chemicals: A review, Renewable and Sustainable Energy Reviews 73 (2017) 346-368.

https://doi.org/10.1016/j.rser.2017.01.142

[48] Kubička, D. and Kikhtyanin, O., 2015. Opportunities for zeolites in biomass upgradingLessons from the refining and petrochemical industry. Catalysis Today, 243, pp.10-22.

https://doi.org/10.1016/i.cattod.2014.07.043

[49] Beyerlein, R. A.; Choi Feng, C.; Hall, J. B.; Huggins, B. J.; Ray, G. J. Effect of Steaming on the Defect Structure and Acid Catalysis of Protonated Zeolites. Top. Catal. 1997, 4, 27

https://doi.org/10.1023/A:1019188105794

[50] L.C. Lerici, M.S. Renzini, L.B. Pierella Chemical catalyzed recycling of polymers: catalytic conversion of PE, PP and PS into fuels and chemicals over H-Y Procedia Mater. Sci., 8 (2015), pp. 297-303 https://doi.org/10.1016/i.mspro.2015.04.076

[51] Marcilla, A., Gomez, A., Garcia, A.N., and Olaya, M.M., Kinetic study of the catalytic decomposition of different commercial polyethylenes over an MCM-41 catalyst J. Anal. Appl. Pyrol., 2002, vol. 64, p. 85. https://doi.org/10.1016/S0165-2370(01)00174-7

[52] H. Gulab, M. R. Jan, J. Shah, G. Manos, Plastic catalytic pyrolysis to fuels as tertiary polymer recycling method: Effect of process conditions, Journal of Environmental Science and Health Part A45 (2010) 908-915 https://www.tandfonline.com/doi/abs/10.1080/10934521003709206

[53] S. Kumar, R.K. Singh Thermolysis of high-density polyethylene to petroleum products J. Petrol. Eng., 2013 (2013), http://dx.doi.org/10.1155/2013/987568

[54] S.L. Wong, N. Ngadi, T.A.T. Abdullah, I.M. Inuwa Conversion of low density polyethylene (LDPE) over ZSM-5 zeolite to liquid fuel Fuel, 192 (2017), pp. 71-82

https://doi.org/10.1016/j.fuel.2016.12.008

[55] Miskolczi, N., Sója, J. and Tulok, E., 2017. Thermo-catalytic two-step pyrolysis of real waste plastics from end of life vehicle. Journal of Analytical and Applied Pyrolysis, 128, pp.1-12. https://doi.org/10.1016/.j.jaap.2017.11.008

[56] Kim, B.S., Kim, Y.M., Lee, H.W., Jae, J., Kim, D.H., Jung, S.C., Watanabe, C. and Park, Y.K., 2016. Catalytic copyrolysis of cellulose and thermoplastics over HZSM-5 and HY. ACS Sustainable Chemistry \& Engineering, 4(3), pp.1354-1363.

https://pubs.acs.org/doi/pdf/10.1021/acssuschemeng.5b01381?rand=2c18u7b2

[57] Song, Y.; Zhu, X.; Xu, L. Study on the process of transformation of olefin into aromatics over HZSM-5. Catal. Commun. 2006, 7 (4), 218-223.

https://doi.org/10.1016/i.catcom.2005.11.007

[58] Valanciene, E., Miknius, L., Martynaitis, V. and Striugas, N., 2017. Influence of equilibrium fluid catalytic cracking catalyst amount on the thermolysis process of various polyolefin plastic 
wastes in a fixed-bed reactor for gasoline and diesel production. Energy \& Fuels, 31(10), pp.11194-11210. https://doi.org/10.1021/acs.energyfuels.7b01472

[59] G. San Miguel, D.P. Serrano, J. Aguado Valorization of waste agricultural polyethylene film by sequential pyrolysis and catalytic reforming Ind Eng Chem Res, 48 (2009), pp. 8697-8703 https://doi.org/10.1021/ie900776w

[60] Serrano, D. P.; Aguado, J.; Escola, J. M.; Rodriguez, J. M.; Peral, A. Catalytic properties in polyolefin cracking of hierarchical nanocrystalline HZSM-5 samples prepared according to different strategies. J. Catal. 2010, 276 (1), 152-160. https://doi.org/10.1016/.j.jcat.2010.09.008

[61] Palza, H.; Aravena, C.; Colet, M. Role of the catalyst in the pyrolysis of polyolefin mixtures and used tires. Energy Fuels 2017, 31, 3111-3120.

https://doi.org/10.1021/acs.energyfuels.6b02660

[62] Zhang, M.; Resende, F. L. P.; Moutsoglou, A. Catalytic fast pyrolysis of aspen lignin via PyGC/MS Fuel 2014, 116, 358- 369 DOI: 10.1016/j.fuel.2013.07.128

[63] O.D. Mante, F.A. Agblevor, S.T. Oyama, R. McClung Catalytic pyrolysis with ZSM-5 based additive as co-catalyst to Y-zeolite in two reactor configurations Fuel, 117 (2014), pp. 649-659 https://doi.org/10.1016/j.fuel.2013.09.034

[64] N. Hosseinpour, Y. Mortazavi, A. Bazyari, A.A. Khodadadi Synergetic effects of Y-zeolite and amorphous silica-alumina as main FCC catalyst components on triisopropylbenzene cracking and coke formation Fuel Process Technol, 90 (2009), pp. 171-179

https://doi.org/10.1016/j.fuproc.2008.08.013

[65] A. A. Lappas, S. Bezergianni, I.A. Vasalos Production of biofuels via co-processing in conventional refining processes Catal Today, 145 (2009), pp. 55-62

https://doi.org/10.1016/..cattod.2008.07.001

[66] J. Schirmer, J. Kim, E. Klemm Catalytic degradation of polyethylene using thermal gravimetric analysis and a cycled-spheres-reactor J. Anal. Appl. Pyrol., 60 (2001), pp. 205-217 https://doi.org/10.1016/S0165-2370(00)00197-2

[67] R. Bagri, P.T. Williams Catalytic pyrolysis of polyethylene J. Anal. Appl. Pyrol., 63 (2001), pp. 29-41. https://doi.org/10.1016/S0165-2370(01)00139-5

[68] G. Yan, X. Jing, H. Wen, S. Xiang, Thermal cracking of virgin and waste plastics of PP and LDPE in a semi-batch reactor under atmospheric pressure, Energy and Fuels, 29(2015) 22892298. https://pubs.acs.org/doi/10.1021/ef502919f

[69] Z. Gao, I. Amasaki, M. Nakada A thermogravimetric study on thermal degradation thermogravimetric study on thermal degradation of polyethylene J. Anal. Appl. Pyrolysis., 67 (2003), pp. 1-9 https://doi.org/10.1016/S0165-2370(02)00010-4

[70] Chen, S., Manos, G. Study of Coke and Coke Precursors During Catalytic Cracking of nHexane and 1-Hexene over Ultrastable Y Zeolite. Catalysis Letters 96, 195-200 (2004).

https://doi.org/10.1023/B:CATL.0000030120.29538.5d

[71] B. Paweewan, P.J. Barrie and L.F. Gladden, Coking and deactivation during $n$-hexane cracking in ultrastable zeolite Y Appl. Catal. A: General 185 (1999) 259.

https://doi.org/10.1016/S0926-860X(99)00143-X

[72] A. A. Brillis and G. Manos, Coke Formation during Catalytic Cracking of $\mathrm{C}_{8}$ Aliphatic Hydrocarbons over Ultrastable Y Zeolite Ind. Eng. Chem. Res. 42 (2003) 2292.

https://doi.org/10.1021/ie020460w

[73] B. Wang, G. Manos A novel thermogravimetric method for coke precursor characterisation J. Catal., 250 (2007), p. 121, https://doi.org/10.1016/j.jcat.2007.05.018

[74] A. Marcilla, A. Gomez-Siurana, F. Valdes Catalytic pyrolysis of LDPE over H-beta and HZSM5 zeolites in dynamic conditions. Study of the evolution of the process J. Anal. Appl. Pyrol., 79 (2007), pp. 433-442 https://doi.org/10.1016/j.jaap.2006.09.006

Appendix $\mathrm{A}_{1}$. GC raw data for the standard $\mathrm{nC}_{5}-\mathrm{nC}_{8}$ and $\mathrm{nC}_{5}-\mathrm{nC}_{8}$ 

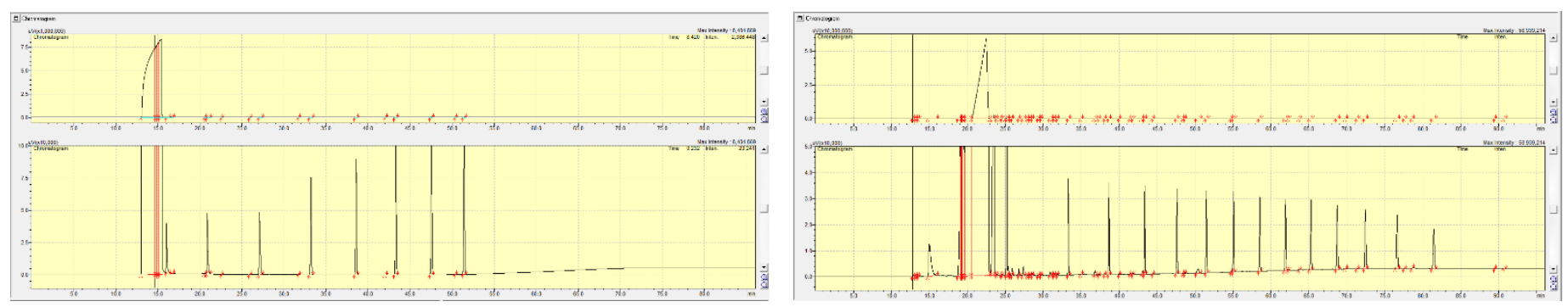

Appendix $A_{2}$ GC raw data for thermal cracking of IIdPE and PP
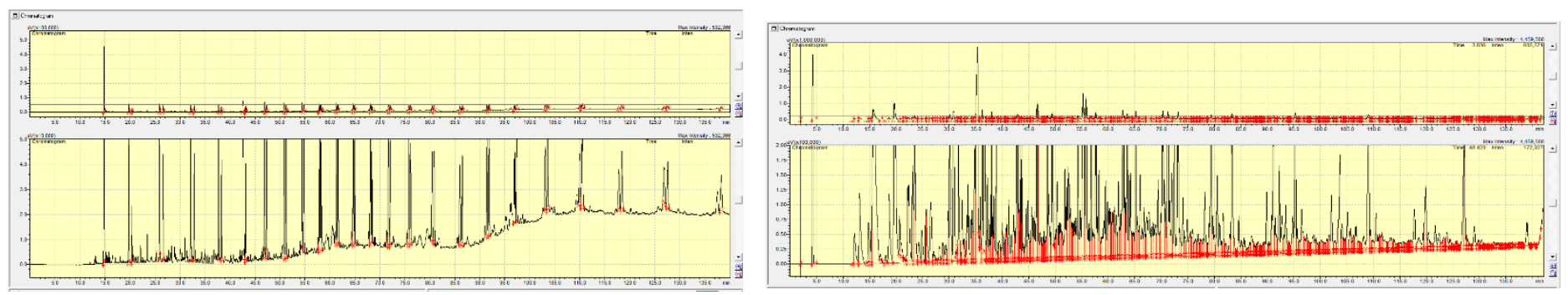

Appendix $A_{3} . \mathrm{GC}$ raw data for catalytic cracking of PP with $\mathrm{HY}$ and USY
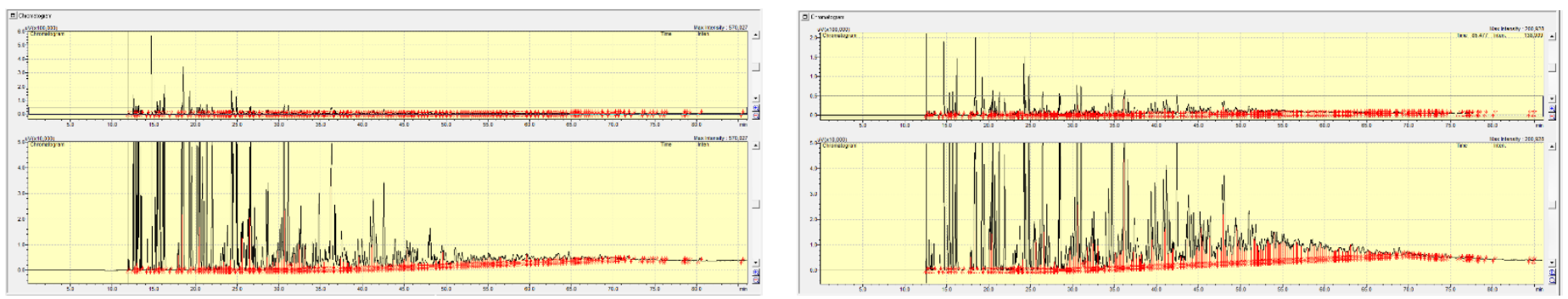

Appendix $A_{4}$. GC raw data for catalytic cracking of PP with ZSM-5 90 and ZSM-5 400
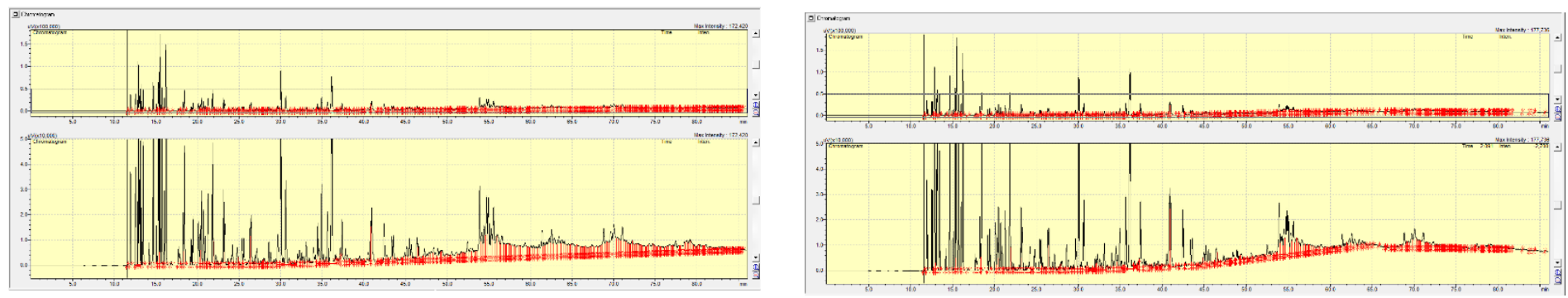
Appendix $A_{5}$. TGA raw data for catalytic cracking of polyethylene with HY zeolite: normal mixing and predegradation treatment
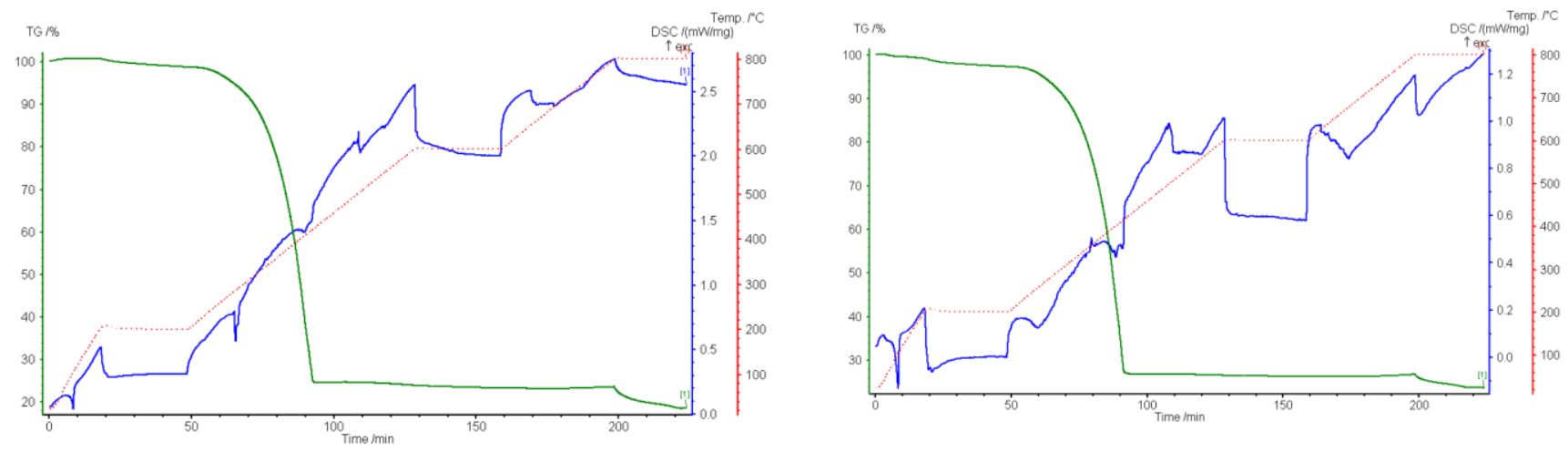

Appendix $A_{6}$. TGA raw data coke characterisation for catalytic cracking of IldPE with HY zeolite: 2:1 and 4:1 ratios, reaction temperature: $723 \mathrm{~K}$
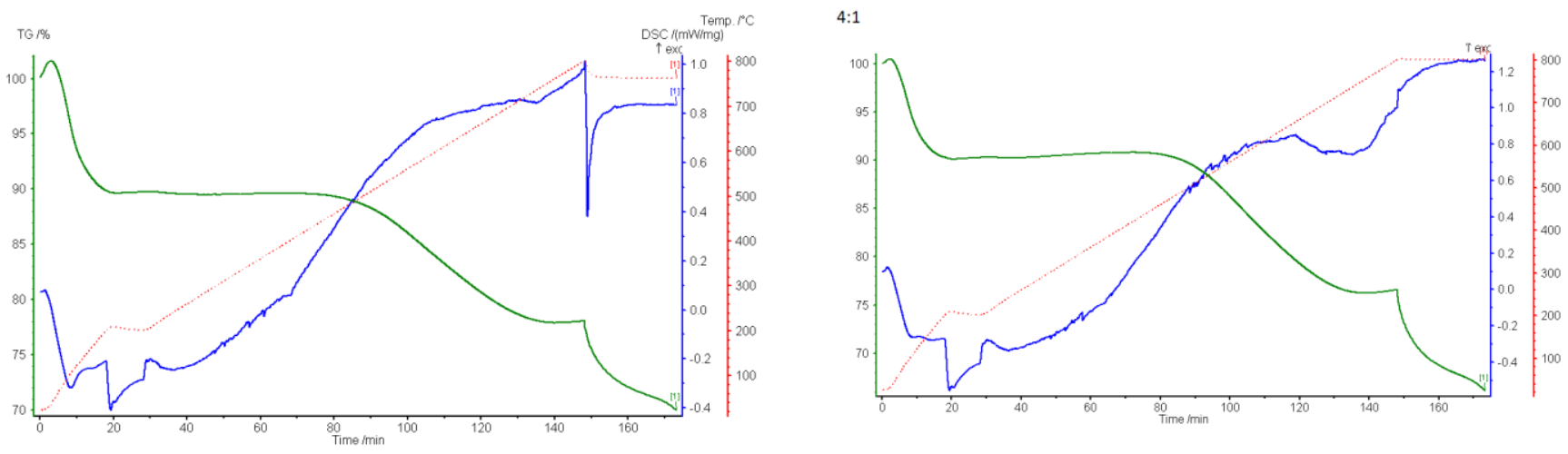